\title{
Dietary treatment of urinary risk factors for renal stone formation. A review of CLU Working Group
}

\author{
Domenico Prezioso ${ }^{1}$, Pasquale Strazzullo ${ }^{1}$, Tullio Lotti ${ }^{1}$, Giampaolo Bianchi ${ }^{2}$, Loris Borghi ${ }^{3}$, \\ Paolo Caione ${ }^{4}$, Marco Carini ${ }^{5}$, Renata Caudarella ${ }^{6}$, Giovanni Gambaro ${ }^{7}$, Marco Gelosa ${ }^{8}$, \\ Andrea Guttilla ${ }^{9}$, Ester Illiano ${ }^{1}$, Marangella Martino ${ }^{10}$, Tiziana Meschi ${ }^{3}$, Piergiorgio Messa ${ }^{8}$, \\ Roberto Miano $^{11}$, Giorgio Napodano ${ }^{12}$, Antonio Nouvenne ${ }^{3}$, Domenico Rendina ${ }^{1}$, Francesco Rocco ${ }^{8}$, \\ Marco Rosa $^{2}$, Roberto Sanseverino ${ }^{12}$, Annamaria Salerno ${ }^{13}$, Sebastiano Spatafora ${ }^{14}$, Andrea Tasca ${ }^{15}$, \\ Andrea Ticinesi ${ }^{3}$, Fabrizio Travaglini ${ }^{5}$, Alberto Trinchieri ${ }^{16}$, Giuseppe Vespasiani ${ }^{11}$, Filiberto Zattoni ${ }^{9}$ \\ ${ }^{1}$ Università Federico II Napoli; ${ }^{2}$ Azienda Ospedaliera-Policlinico di Modena; ${ }^{3}$ Università degli Studi di Parma; \\ ${ }^{4}$ Ospedale Pediatrico Bambino Gesù di Roma; ${ }^{5}$ Azienda Ospedaliero Universitaria di Careggi, Firenze; ${ }^{6}$ Casa di Cura Villalba, \\ Bologna; ${ }^{7}$ Università Cattolica Sacro Cuore di Roma; ${ }^{8}$ Fondazione IRCCS Ca' Granda Ospedale Maggiore Policlinico, Milano; \\ ${ }^{9}$ Università degli Studi di Padova; ${ }^{10}$ A.O. Ordine Mauriziano di Torino; ${ }^{11}$ Fondazione IRCCS Ca' Granda Ospedale Maggiore \\ Policlinico, Milano; ${ }^{11}$ Università di Roma Tor Vergata; ${ }^{12}$ Ospedale Umberto I, Nocera Inferiore, Salerno; ${ }^{13}$ Università \\ Campus Biomedico, Roma; ${ }^{14}$ Arcispedale Santa Maria Nuova, Reggio Emilia; ${ }^{15}$ Ospedale San Bartolo di Vicenza; \\ ${ }^{16}$ Ospedale A. Manzoni di Lecco.
} \begin{abstract}
Summary
$\begin{aligned} & \text { Objective: Diet interventions may reduce the risk } \\ & \text { of urinary stone formation and its recurrence, but }\end{aligned}$ there is no conclusive consensus in the literature regarding the effectiveness of dietary interventions and recommendations about specific diets for patients with urinary calculi. The aim of this study was to review the studies reporting the effects of different dietary interventions for the modification of urinary risk factors in patients with urinary stone disease.

Materials and Methods: A systematic search of the Pubmed database literature up to July 1, 2014 for studies on dietary treatment of urinary risk factors for urinary stone formation was conducted according to a methodology developed a priori. Studies were screened by titles and abstracts for eligibility. Data were extracted using a standardized form and the quality of evidence was assessed.

Results: Evidence from the selected studies were used to form evidencebased guideline statements. In the absence of sufficient evidence, additional statements were developed as expert opinions.

Conclusions: General measures: Each patient with nephrolithiasis should undertake appropriate evaluation according to the knowledge of the calculus composition. Regardless of the underlying cause of the stone disease, a mainstay of conservative management is the forced increase in fluid intake to achieve a daily urine output of 2 liters.

Hypercalciuria: Dietary calcium restriction is not recommended for stone formers with nephrolithiasis. Diets with a calcium content $\geq 1$ g/day (and low protein-low sodium) could be protective against the risk of stone formation in hypercalciuric stone forming adults. Moderate dietary salt restriction is useful in limiting urinary calcium excretion and thus may be helpful for primary and secondary prevention of nephrolithiasis. A low-normal protein intake decrease calciuria and could be useful in stone prevention and preservation of bone mass. Omega-3 fatty acids and bran of different origin decreases calciuria, but their impact on the urinary stone risk profile is uncertain. Sports beverage do not affect the urinary stone risk profile. Hyperoxaluria: A diet low in oxalate and/or a calcium intake normal to high (800-1200 $\mathrm{mg} /$ day for adults) reduce the urinary excretion of oxalate, conversely a diet rich in oxalates and/or a diet low in calcium increase urinary oxalate. A restriction in protein intake may reduce the urinary excretion of oxalate although a vegetarian diet may lead to an increase in urinary oxalate. Adding bran to a diet low in oxalate cancels its effect of reducing urinary oxalate. Conversely, the addition of supplements of fruit and vegetables to a mixed diet does not involve an increased excretion of oxalate in the urine. The intake of pyridoxine reduces the excretion of oxalate. Hyperuricosuria: In patients with renal calcium stones
\end{abstract}

the decrease of the urinary excretion of uric acid after restriction of dietary protein and purine is suggested although not clearly demonstrated. Hypocitraturia: The administration of alkaline-citrates salts is recommended for the medical treatment of renal stone-formers with hypocitraturia, although compliance to this treatment is limited by gastrointestinal side effects and costs. Increased intake of fruit and vegetables (excluding those with high oxalate content) increases citrate excretion and involves a significant protection against the risk of stone formation. Citrus (lemons, oranges, grapefruit, and lime) and non citrus fruits (melon) are natural sources of dietary citrate, and several studies have shown the potential of these fruits and/or their juices in raising urine citrate levels. Children: There are enought basis to advice an adequate fluid intake also in children. Moderate dietary salt restriction and implementation of potassium intake are useful in limiting urinary calcium excretion whereas dietary calcium restriction is not recommended for children with nephrolithiasis. It seems reasonable to advice a balanced consumption of fruit and vegetables and a low consumption of chocolate and cola according to general nutritional guidelines, although no studies have assessed in pediatric stone formers the effect of fruit and vegetables supplementation on urinary citrate and the effects of chocolate and cola restriction on urinary oxalate in pediatric stone formers. Despite the low level of scientific evidence, a low-protein $(<20 \mathrm{~g} /$ day $)$ low-salt $(<2 \mathrm{~g} /$ day) diet with high hydration ( $>3$ liters/day) is strongly advised in children with cystinuria. Elderly: In older patients dietary counseling for renal stone prevention has to consider some particular aspects of aging. A restriction of sodium intake in association with a higher intake of potassium, magnesium and citrate is advisable in order to reduce urinary risk factors for stone formation but also to prevent the loss of bone mass and the incidence of hypertension, although more hemodynamic sensitivity to sodium intake and decreased renal function of the elderly have to be considered. A diet rich in calcium (1200 $\mathrm{mg} /$ day) is useful to maintain skeletal wellness and to prevent kidney stones although an higher supplementation could involve an increase of risk for both the formation of kidney stones and cardiovascular diseases. A lower content of animal protein in association to an higher intake of plant products decrease the acid load and the excretion of uric acid has no particular contraindications in the elderly patients, although overall nutritional status has to be preserved.

KEY WORDS: Urinary calculi; Dietary treatment; Urinary risk factors; Hypercalciuria; Hyperoxaluria; Hypocitraturia; Children; Elderly.

Submitted 1 February 2015; Accepted 30 April 2015 


\section{INTRODUCTION}

(Domenico Prezioso, Pasquale Strazzullo,

Domenico Rendina, Ester Iliano)

Nephrolithiasis (NL) affects $5-15 \%$ of the population worldwide with a recurrence rate higher than $50 \%$. It does not spare any geographical, cultural, or racial group. An increase in NL incidence and prevalence has been observed in the final quarter of the last century in both genders $(1,2)$. Approximately $80 \%$ of all kidney stones are composed of calcium salts, namely calcium-oxalate $(\mathrm{CaOx})$ and calcium phosphate $(\mathrm{CaP})(3)$. The tendency to form $\mathrm{CaOx}$ stones is directly related to urinary concentrations of calcium, oxalate and urate, and inversely associated with those of magnesium and citrate. In addition to these metabolic risk factors, also the urinary concentrations of phosphate and hydrogen ions $(\mathrm{pH})$ plays a role in the pathogenesis of $\mathrm{CaP}$ stones $(3,4)$. A significant percentage of the remaining stones is composed of uric acid (UA), which accounts for over 10\% of all kidney stones. UA stones form in the presence of an abnormally low urine $\mathrm{pH}$ (4). Recent epidemiological data indicate that NL is a significant risk factor for chronic and end stage kidney disease (5-6).Both environmental and genetic factors synergistically contribute to the pathogenesis of the different types of stones (2-4). The role of inheritance is obvious in monogenic diseases such as cystinuria, Dent's disease and primary hyperoxaluria (4), but also "idiopathic" stone formation show a familial tendency (7). Among environmental factors, dietary habits appear to play an important role in the pathogenesis of NL and are likely responsible for its growing incidence in the last few decades (8-9). Indeed, NL is considered a systemic disorder associated with a group of cardio-metabolic conditions such as obesity, diabetes, hypertension, metabolic syndrome and coronary artery disease (10-13), all of them in turn related to nutritional inadequacies. The NL- directly related costs exceed 5 billion dollars each year in the United States. Thus, the development of (scientifically sound) dietary recommendations for primary and secondary NL prevention should be seen as one of the most promising cost-saving actions in the clinical management of NL (5).

\section{Patient evaluation}

Each patient with NL should undertake appropriate morpho-functional evaluation $(3,7,14,15)$. The classification of NL is based on the composition of renal calculi because the different types of stones present different etiologies and pathogeneses that require a different therapeutic approach. Based on the clinical history of the disease, it is also important to distinguish relapsing forms, from those associated with metabolic syndrome (MS) and those at particularly risk of systemic complications such as chronic kidney disease (CKD) and metabolic bone disease (MBD). Relapsing NL is diagnosed if the patient experienced $\geq 3$ new episodes of kidney stones in the past 5 years, although even a patient with first-episode, showing more calculi in one or both kidneys, should be classified as a relapsing patient. The general practitioner (GP) is the professional figure most often involved in the initial diagnostic evaluation of the patient. Indeed, a well conducted history and a limited number of step one laboratory tests allow to identify several secondary forms of NL and to select patients with MS and those at increased risk of CKD or MBD. The medical history will provide information on i) degree of disease activity over the past 5 years, ii) familiarity of the disease, iii) dietary habits and lifestyle. Although a comprehensive nutrition survey must be attended by skilled personnel and requires the use of dedicated software, the formulation of a few questions may provide in most cases enought information about the lithogenic risk associated with the patient's dietary habits. Information should be obtained about average caloric intake, amount and type of ingested liquids and the habitual intake of salt, animal protein, carbohydrates, potassium, calcium and oxalate-rich foods.

Step 1 metabolic investigation includes: blood tests (creatinine, urea, glucose, uric acid, $\mathrm{Na}, \mathrm{K}, \mathrm{Cl}$, calcium, phosphorus, lipid profile); urine tests (complete urinalysis and urine culture for common germs); ultrasound abdomen examination; analysis of stone composition. This step thanks to execution simplicity and low costs, may be applied on almost all NL patients and allows one to select patients requiring more advanced step two assessment.

Step 2 evaluation may more often require collaboration with a specialist. It will include again: blood tests (parathyroid hormone (PTH), 25 and possibly 1,25 vitamin D, magnesium, alkaline phosphatase); 24 hour urine collection for creatinine, urate, sodium, potassium, chloride, calcium, phosphate, magnesium, citrate, $\mathrm{pH}$, sulphate and ammonium. The 24 hour urine analysis should be repeated annually to assess the patients adherence to treatment. In the case of calcium NL a bone mineral density assessment by DEXA may be of value. Diagnostic Imaging workup is based on: abdomen X-ray and ultrasonographic examination, which in combination allow to recognize 90\% of cases of NL; echo-color-Doppler examination with measurement of the resistance index to detect urine flow obstruction; urography, currently used only before surgical treatment, endoscopy and lithotripsy or in other particular circumstances; non contrast computed tomography (NC CT, used for diagnostic emergency in patients with renal colic, allowing detection of all types of calculi or their indirect signs; Uro CT, which consists in a normal CT scan of the abdomen exploiting the early stage of impregnation for the study of the kidneys and the bladder; ascending or descending pielography, to be performed only in the context of operating procedures, e.g. ureterorenoscopy; sequential renal scintiscan, that is still the most reliable method for the assessment of impairment of individual renal unit and degree of obstruction, if present; magnetic resonance imaging (MRI) to be preferred whenever the radiation burden involved with other procedures is of concern (e.g. pregnant and pediatric patients).

\section{Stone analysis}

There are two main categories of urinary stones: calcium stones and no-calcium stones, which are both the consequence of crystallization and aggregation of highly concentrated urinary components. Although stone composition analysis is not always feasible or achievable, there is helpful information from such an investigation that can aid for prevention of recurrences. For instance, as shown by a well performed randomized controlled trial (16), calcium phosphate or brushite stones may be associated to primary 
hyperparathyroidism (HPT) and renal tubular acidosis (RTA), calcium oxalate stones may be associated to chronic diarrhoea, acid uric stones to gouty diathesis, struvite stones to urinary infection and cystine stones to urinary cystine excretion. These associations are particularly evident in the case of non-calcium stones, as also shown by Kourambas et al. (17), who found that patients with no-calcium stones were found to have specific metabolic disorders according to the type of analysed calculi, whereas patients with calcium stones were more heterogeneous with regard to concomitant metabolic disorders.

Knowledge of the calculus composition may help the physician to prescribe of the most appropriate diagnostic workup and with the implementation of adequate dietary and therapeutic measures (18). Namely, should the urine be alkalinized? Will the stone be amenable to extracorporeal shock wave lithotripsy or should ureteroscopy or percutaneous lithotripsy be attempted? Stone composition analysis should be performed in all first-time stone formers and repeat stone analysis is needed in case of recurrence under pharmacological prevention, early recurrence after interventional therapy with complete stone clearance, late recurrence after a prolonged stone-free period (19).

The methods currently available for the of stone composition analysis are: i) chemical analysis (now deemed obsolete because of its major limitations), thermogravimetry, emission spectroscopy, polarizing spectroscopy, X-ray diffraction, X-ray coherent scatter/crystallography, scanning electron microscopy, and infrared spectroscopy (20). The ones preferred are infrared spectroscopy and X-ray diffraction (21-23). X-ray diffraction uses monochromatic X-rays for identifying the constituents of a renal stone based on the unique diffraction patterns produced by a crystalline material (24). Infrared (IR) spectroscopy uses IR radiation in order to cause atomic vibrations energy absorption and final appearance of absorption bands in the IR spectrum of stone samples 24). Equivalent results can be obtained by polarisation microscopy, based on the interaction of polarized light with stone crystals, which however is limited to centers with special expertise (25). In addition to the above mentioned commonly used techniques, there are other techniques which may unravel more detailed information on the molecular structure of the stone nuclear region (26). These techniques are not used in routine diagnostic laboratories for being costly and requiring special expertise or sample preparation. Studies involving the use of single-energy CT technology have shown that valuable information about stone composition may be gained, enabling differentiation between uric acid and calcium stones on the basis of their different attenuations (27). Dual-energy CT by low and high-energy scanning is capable to differentiate various materials with similar electron densities but different photon absorption (27), thus contributing to the chemical characterization of stones for the purpose of surgical or medical treatment decision.

\section{Water intake}

For all NL patients, regardless of the underlying cause of the stone disease, a mainstay of conservative management is to force the increase in fluid intake to achieve a daily urine output of 2 litres (28). Theoretically, increased urine output may have two effects. First, the ensuing mechanical diuresis may prevent urine stagnation and formation of symptomatic stones. More important, the dilute urine alters the supersaturation of stone components.

Modification of the concentration of lithogenic factors is indeed the focus of stone prevention. The effect of urinary dilution on crystallization of stone-forming salts was first evaluated by Pak et al. (2), who showed that an increased fluid intake and the subsequent urine dilution had a protective effect on the crystallization of calcium salts (29). Currently, no evidence is available with regard to the actual benefit of increasing water intake for primary prevention of urinary stones, however there is a randomised controlled trial evidence of benefit from increasing water intake for the prevention of stone recurrences (30). In the trial by Borghi and co-workers, participants randomized to $>2 \mathrm{l} / \mathrm{d}$ of water intake were significantly less likely to have stone recurrence over 5 years and a much longer time to recurrence compared with the untreated control group (30). In another study by Sarica et al. on NL patients who underwent shockwave lithotripsy and were currently stone-free, those randomized to increased fluid intake to achieve a urine output of $>2.5 \mathrm{l} / \mathrm{d}$ for $2-3$ years had a stone recurrence rate of $8 \%$ compared with $56 \%$ of those allocated to no treatment (31). A study by Frank et al. compared the incidence of urinary stones in two desert towns after an educational program had been run in one of them for increasing water intake as a preventive measure against the risk of NL. Upon a 3-yr follow-up, the prevalence of urinary stones was significantly lower in the intervention town $(0.28 \%$ versus $0.85 \%)$ (32). Similar findings have been provided by a long-term study in the US (33).

It has long been debated whether differences in drinking water characteristics, namely water hardness, fixed residue and saline components may impact on the risk of renal stones. Whereas Coen et al. reported that an increase in water hardness resulted in higher incidence of NL (34), in most other studies greater water hardness, i.e, mineral content, has been associated with beneficial effects in preventing stone events, probably through different mechanisms, including the increase in urinary citrate (35-38). Confounding factors may explain the discrepancies in results. Karagülle et al., found that bicarbonate-rich mineral water had a positive effect on calcium oxalate urine supersaturation (38), probably due to increased $\mathrm{pH}$ (in a range opposing calcium oxalate stone formation) and to greater concentration of the inhibitory factors citrate and magnesium. This finding was confirmed in the study by Bertaccini et al. who showed that the intake of a water with medium mineral (calcium $119.7 \mathrm{mg} / \mathrm{l}$ ) and high bicarbonate $(412 \mathrm{mg} / \mathrm{l})$ content causes specific changes of urinary composition that could be beneficial to prevent stone formation (39), the bicarbonate load increasing urinary $\mathrm{pH}$ and urinary citrate excretion. The latter can indeed be helpful for prevention of both uric acid lithiasis, thanks to the higher urinary $\mathrm{pH}$ with increased solubility of uric acid, and calcium lithiasis, as a consequence of the increased urinary citrate concentration, with inhibition of calcium crystal formation and aggregation. The higher potassium content of mineral water also promoted urinary alkalization and led to further increase in urinary citrate excretion (39). According to Siener et al. also the magnesium content of mineral water results in favourable 
changes in urine composition, namely a higher urinary magnesium concentration (40).

\section{Materials and Methods}

The CLU working group conducted a systematic search of the Pubmed database literature up to July 1, 2014 for studies on dietary treatment of urinary risk factors for urinary stone formation. Reviewers were divided in 5 groups for searching about dietary intervention for treatment of hypercalciuria (group 1), hyperoxaluria and hyperuricosuria (group 2), hypocitraturia (group 3) and about dietary prevention of urinary calculi in the child (group 4) and in the elderly (group 5). Search terms were reported in Table 1. According to a methodology developed a priori meta-analyses, randomized controlled trials, case control and cohort studies were included. Review studies and case reports were excluded. Additional articles were identified from reference lists of relevant articles or, if necessary, by other more specific search strategies. Three or more reviewers for each group independently screened titles and abstracts of studies for potential eligibility. The quality of evidence was assessed using the Grading of Recommendations Assessment, Development and Evaluation (GRADE) framework. The reviewers extracted data using a standardized form. The following data were abstracted: type of study, characteristics of trial participants (number, gender, healthy/RSFs); type of intervention; outcomes and quality of evidence.

\section{RESULTS}

Summary of findings tables were built for defined outcomes (posted in Supplementary Materials on www.aiua.it). Results of the selected studies were used to form evidencebased guideline statements. In the absence of sufficient evidence, additional statements were developed as expert opinions.

\section{Discussion and Conclusions}

\section{Dietary treatment of hypercalciuria}

(Marco Rosa, Giovanni Gambaro, P. Manuel Ferraro, Giampaolo Bianchi, Domenico Rendina, Andrea Tasca) Generally speaking available literature is of very low quality data. Quite few randomized clinical trials (RCTs) have been done, most of them with significant methodological limitations. They are addressed in depth by a recent
Cochrane review (1) which concluded that "...no compelling evidence was identified to support the use of dietary interventions to reduce the risk of complications [essentially the effect on stone rate or on the urinary stone risk profile] among people with idiopathic hypercalciuria...." also noticing that "... Overall, the quality of the evidence supporting dietary interventions is poor...". The Cochrane review considered 5 RCT; however, in the present systematic review of the literature we decided not to consider 2 of them because the dietary intervention was indeed a "pharmacological" treatment with the herbal extract Phyllantus niruri (2) or because the total intake of calcium was not controlled (3). However, a number of observational or non-controlled interventional studies, either retrospective or prospective on urinary stone risk-factors (mainly variations in calciuria and/or oxaluria) can be retrieved. We obtained from specialized registers 374 articles of which 26 have been considered in the present statement.

1. Dietary calcium restriction is not recommended for stone formers with nephrolithiasis. Diets with a calcium content $\geq 1$ g/day (and low protein-low sodium) could be protective against the risk of stone formation in hypercalciuric stone forming adults.

A cross-sectional study in stone formers has shown that higher calcium intakes at levels typically observed in freeliving individuals are associated with only small increases in calciuria (3). A previous observational cohort prospective study in healthy men had disclosed that a high dietary calcium intake decreases the risk of symptomatic kidney stones (4). A retrospective, uncontrolled longitudinal study (very low quality data) on the effect of a calcium restricted diet in hypercalciuric and normocalciuric stone formers concluded that secondary rise in urinary oxalate occurring from calcium restriction can be avoided by concurrent dietary oxalate restriction; the effect on urinary saturation of calcium oxalate was modest (6). Another uncontrolled longitudinal study (retrospective of very low quality) in hypercalciuric stone formers reported that low calcium diet only marginally decrease calciuria and did not modify fasting hypercalciuria (7). In an uncontrolled descriptive study, in 50\% of patients who were hypercalciuric on a free diet, when assuming a $1000 \mathrm{mg} / \mathrm{d}$ calcium diet (higher content than in the free diet) calcium excretion fell markedly or normalized (8). An uncontrolled longitudinal, prospective study has shown that, on a low-calcium diet, absorptive hypercalciuric patients are particularly prone to develop hyperoxaluria (9).

In an observational cohort study (prospective) oxaluria

Table 1. Search Pubmed terms.

\begin{tabular}{|c|c|c|c|c|}
\hline Group & Search terms & Papers $n^{\circ}$ & Selected & Added \\
\hline 1 & (urinary calculi OR kidney stones OR renal stones OR nephrolithiasis OR urolithiasis) AND diet AND hypercalciuria & 374 & 26 & 0 \\
\hline \multirow[t]{2}{*}{2} & (urinary calculi OR kidney stones $\mathrm{OR}$ renal stones $\mathrm{OR}$ nephrolithiasis $\mathrm{OR}$ urolithiasis) AND diet AND hyperoxaluria & 183 & 37 & 3 \\
\hline & (urinary calculi $\mathrm{OR}$ kidney stones $\mathrm{OR}$ renal stones $\mathrm{OR}$ nephrolithiasis $\mathrm{OR}$ urolithiasis) AND diet AND hyperuricosuria & 75 & 6 & 0 \\
\hline 3 & (urinary calculi OR kidney stones OR renal stones OR nephrolithiasis OR urolithiasis) AND diet AND hypocitraturia & 54 & 5 & 19 \\
\hline 4 & (urinary calculi OR kidney stones OR renal stones OR nephrolithiasis OR urolithiasis) AND diet AND children & 197 & 38 & 0 \\
\hline 5 & (urinary calculi OR kidney stones OR renal stones OR nephrolithiasis OR urolithiasis) AND diet AND elderly & 597 & 3 & 19 \\
\hline
\end{tabular}


was significantly reduced after one week treatment with calcium $1 \mathrm{~g} /$ day in stone formers who were usually on a regular low calcium diet $(<500 \mathrm{mg} /$ day $)$ but not in those with diet-dependent hypercalciuria (10). With a similar experimental design in hypercalciuric stone patients, the same group did not show a significant additional increase in urinary calcium (11). In an uncontrolled longitudinal prospective study in hypercalciuric idiopathic stone formers an intake of a high-calcium diet for 5-6 days reduced urinary oxalate and the probability of being a stone former according to PSF index (12). In a 4 weeks randomized controlled trial (RCT) in absorptive hypercalciuric stone formers, a low calcium $(<500 \mathrm{mg} /$ day $)$, normal protein and salt diet did not significantly modify the urine risk profile for stone formation while possibly inducing an increased bone turn-over (13). In an uncontrolled longitudinal 4-week prospective study in calcium stone formers a low calcium diet (440 mg/day) decreased calciuria but increased the urine supersaturation for calciumoxalate also in hypercalciuric patients (14). In an uncontrolled longitudinal prospective study on idiopathic hypercalciuria, a combined low calcium, low oxalate diet did not significantly decreased the PSF (15). A RCT has shown that in hypercalciuric stone formers with a 2-3 L/day water intake, a diet with calcium $1200 \mathrm{mg} /$ day, together with reduced protein (less than 15\% caloric intake) and salt ( $<50 \mathrm{mmol} /$ day $)$ was superior in reducing stone recurrences versus a $400 \mathrm{mg} /$ day low calcium diet (16). In this study, however, it is difficult to dissect the preventive role of the different components of the diets (normal calcium versus low protein versus low salt). Furthermore, it is difficult to understand if the positive results were due to the favourable effects of this latter diet alone, or the results were magnified by a particularly unfavourable diet as the low-calcium diet.

2. Moderate dietary salt restriction is useful in limiting urinary calcium excretion and thus may be helpful for primary and secondary prevention of nephrolithiasis.

A RCT trial in hypercalciuric stone formers with high baseline sodium intake, a low-salt $(<60 \mathrm{mmol} / \mathrm{d}$ sodium, or $<3.5 \mathrm{~g} / \mathrm{d} \mathrm{NaCl})$ normocalcic $(800-1000 \mathrm{mg} / \mathrm{d})$ diet reduced calcium excretion (17).

3. A low-normal protein intake decreases calciuria and could be useful in stone prevention and preservation of bone mass.

In a short term uncontrolled longitudinal prospective study on a small cohort of hypercalciuric stone formers a diet with an intake of $0.8 \mathrm{~g}$ of protein per $\mathrm{Kg}$ of body weight and normal calcium intake decreased calciuria and a number of bone and stone risk factors possibly because of a reduced acid load (18). This observation is in keeping with the study by Borghi at al. (16) and with a number of observations in healthy non-stone forming people.

4. Omega-3 fatty acids decrease calciuria, but the impact on the urinary stone risk profile is uncertain.

Although an observational cohort study of moderate quality disclosed in healthy non-stone forming people that greater levels of arachidonic and linoleic acid intake do not increase the risk for developing a kidney stone, and greater intake of Omega-3 fatty acids does not reduce the risk (based on a food frequency questionnaire) (19), very low quality data may suggest that the administration Omega-3 fatty acids of fish oli alone or combined with empiric dietary counseling decrease urinary calcium in hypercalciuric stone formers (20-22). However, the impact of Omega-3 administration on the risk profile for recurrent nephrolithiasis may be limited (20).

5. Bran of different origin decreases calciuria, but the impact on the urinary stone risk profile is uncertain.

In a descriptive study on idiopathic hypercalciuric patients, rice bran ( $10 \mathrm{~g}$ twice daily) for 1 month to 3 years decreased calciuria (23). In a very small uncontrolled longitudinal, prospective study Farmolith (a granular powder consisting of different dietary fibres) decreased calciuria and oxaluria in absorptive hypercalciuric stone patients (24). Wheat bran (14 g) assumed in each of the 2 main meals in stone formers with absorptive hypercalciuria decreased calciuria without changing oxaluria in a small uncontrolled longitudinal 90 days study (25). In a small RCT on hypercalciuric stone formers, $30 \mathrm{~g}$ of dietary fiber as unprocessed wheat bran in association with a low calcium-low oxalate diet induced a $23.5 \%$ decrease in calciuria in comparison with only a $5.6 \%$ reduction obtained with diet alone; however, oxaluria was decreased $21.4 \%$ by diet alone compared with only $3.9 \%$ in the diet and fiber treatment group (26).

6. Sports beverage do not affect the urinary stone risk profile. Carbohydrate-electrolyte sports beverages (Gatorade) in a prospective crossover study on healthy and stone forming patients had no effect on urinary calcium or other urine stone risk parameters (27).

Dietary treatment of hyperoxaluria (Martino Marangella, Fabrizio Travaglini, Alberto Trinchieri)

Dietary oxalate and its precursors

1. In human experiments, the intestinal absorption of oxalate is greater on a diet high in oxalate $(600 \mathrm{mg}) \mathrm{com}$ pared to that on a diet poor in oxalate $(63 \mathrm{mg})$, although there is an adaptation with lower rate of absorption if the diet with a high content of oxalate continues for over 6 weeks (Zimmermann 2005 experimental controlled study M) (1)

2.. A diet rich in oxalate causes a significant increase in urinary oxalate levels (Butz 1980 - experimental study M, Massey 1993- experimental study M, Siener 2003 - observational study L, de O G Mendonça 2003 - RCT M) (2-5).

3. A diet low in oxalate is effective in reducing urinary excretion of oxalate and urinary saturation for calcium oxalate with respect to a basal free choice diet (Kirac 2013 Experimental non controlled - M; Laminski 1991 experimental non controlled - M) $(6,7)$.

4. In patients with idiopathic calculi an intake of ascorbic acid $>1 \mathrm{~g}$ /day is more frequent than in controls (Griffith 1986 case-control observational study - L) (8). A load of ascorbic acid may lead to an increase in serum and urinary levels of oxalate by increasing the intestinal absorption and endogenous synthesis. In total parenteral nutrition (TPN) an increase of ascorbic acid infusion from 100 to $200 \mathrm{mg}$ induces an increase of oxaluria of about $0.10 \mathrm{mmol} /$ day. (Pena de la Vega, 2004 experimental study M) (9).

5. The increase of oxaluria after oral ingestion of large 
amounts of ascorbic acid is not well predictable and has not been confirmed unanimously but it was suggested that patients at risk of kidney stones should not exceed an intake of $500 \mathrm{mg} /$ day (Butz 1980, Massey 2005 M experimental studies $M)(2,10)$.

\section{Dietary calcium (and magnesium)}

6. Epidemiological studies have shown that the excretion of oxalate is inversely related to dietary intake of magnesium (Eisner 2012 - observational cohort study L) (11) and calcium (Trinchieri 1998 observational cohort study L) (12). 7. The rate of intestinal absorption of oxalate, evaluated with [ 13C2] oxalate in healthy volunteers on a diet containing $800 \mathrm{mg}$ of calcium, ranges between 2.2 and $18.5 \%$. The intra-individual variation is wide $(3.4 \pm 1.7 \%)$ (von Unruh, 2003 - experimental study M) (13).

8. The intestinal absorption of radioactive $\left[{ }^{13} \mathrm{C}_{2}\right]$ oxalate in a diet containing $1200 \mathrm{mg}$ of calcium (diet + supplements of calcium citrate and calcium carbonate) is $2 \%$, but it increases to $17 \%$ at $200 \mathrm{mg}$ of dietary calcium. The increase is linear with the decrease of dietary calcium, but there is no further reduction of intestinal absorption of oxalate when dietary calcium increases > $1200 \mathrm{mg}$ (Von Unruh, 2004 - experimental study M) (14).

9. In healthy subjects and calcium renal stone formers a low-calcium diet causes a significant decrease in the levels of urinary calcium but increases urinary excretion of oxalate and the risk of renal stone formation (Bataille 1983 - experimental non controlled study M) (15).

10. In idiopathic renal calcium stone formers with hypercalciuria a low calcium diet increases urinary oxalate excretion more than in normocalciuric. On low calcium diet urinary oxalate excretion is related to the degree of intestinal absorption of calcium (Jaeger 1985 - experimental non controlled $M)$ (16).

11. In renal stone formers with idiopathic hypercalciuria a high-calcium diet (900-1070 mg/day) decreases the excretion of oxalate, the oxalate/creatinine ratio and the lithogenic risk in comparison with a normal-calcium diet (700 mg/day) (Brown 1987 experimental non controlled study - L, Nakada 1988 experimental non controlled study - M) $(17,18)$. 12. In calcium oxalate renal stone patients with hyperoxaluria the addition of supplements of calcium citrate to the low-oxalate diet did not result in a greater decrease of urinary excretion of oxalate than diet alone, although the supersaturation for calcium oxalate decreases more significantly (Penniston, 2009 experimental non controlled M) (19).

\section{Vegetarian}

13. Vegetarians have higher urinary oxalate levels than controls on a free-choice mixed mediterranean diet with significantly higher calcium/oxalate ratio resulting from an higher intake of oxalate and increased fractional intestinal absorption of oxalate (Marangella 1989 - observational study L) (20).

14. In vegetarians the risk of calcium oxalate crystallization is not decreased (increase in urinary $\mathrm{pH}$, citrate and magnesium excretion and decline in calcium excretion, but increase in urinary oxalate by 30\%) (Siener R, 2002 - experimental non controlled study M) (21).

Fruit and vegetables

15. In patients with hyperoxaluria ( $>40 \mathrm{mg}$ ), the diet rich in fruits, vegetables, whole grains and low-fat dairy products and low in total fat and saturated fat, cholesterol, refined carbohydrates and sweets and meat, which is recommended for patients with hypertension (Dietary Approaches to Stop Hypertension - DASH) results in a slight increase in urinary excretion of oxalate compared with a diet low in oxalates, but decreases the supersaturation with respect to calcium oxalate due to the concomitant increase in excretion of magnesium and citrate and increase of urinary pH (Noori 2014 - RCT H) (22).

16. In normal healthy subjects the abolition of fruits and vegetables induces a slight increase of calcium oxalate and calcium phosphate saturation as it reduces excretion of citrate, magnesium, potassium and also oxalate, while increasing urinary excretion of calcium and ammonium. In hypocitraturic calcium renal stone formers, adding fruits and vegetables increases excretion of magnesium and citrate, urinary $\mathrm{pH}$ and urinary volume, without changing excretion of oxalate and calcium. The result is a significant reduction of lithogenic risk for calcium salts and for uric acid (Meschi 2004 - experimental non controlled study M) (23).

Protein

17. A moderate load of glycine ( $4.5 \mathrm{~g}$ daily) or protein (50 $\mathrm{g}$ daily, $50 \%$ animal protein) has no effect on serum or urinary oxalate (Butz 1980 - experimental non controlled study M) (2)

18. A diet very rich in meat (700 g of meat or fish daily, $2.26 \mathrm{~g}$ of protein $/ \mathrm{kg}$ daily) increases urinary oxalate in approximately one third of patients with calcium nephrolithiasis, with an average increase of $73 \mu \mathrm{mol} / 24 \mathrm{~h}$ whereas no change is observed in normal subjects. Patients with mild hyperoxaluria have a more substantial increase of urinary oxalate $(+100 \mu \mathrm{moli})$. The mechanism of sensitivity is not clear, but does not involve deficit in vitamin B6 (Nguyen 2001 - experimental non controlled study M) (24).

19. The effect of a reduction in dietary protein on urinary excretion of oxalate is controversial. Changing calcium stone-formers from a high to a low animal protein intake causes no variation in urinary oxalate (Marangella 1989 observational study L) (20). In renal stone formers with idiopathic hypercalciuria a moderate restriction of protein intake causes a reduction of urinary calcium, urate and oxalate and improves the profile of lithogenic patients (Giannini 1999 experimental non controlled study M) (25). A diet with reduced intake of protein $(<93 \mathrm{~g})$ and salt $(50$ $\mathrm{mmol}$ ) results in a significant reduction of urinary oxalate excretion and calcium oxalate product (Borghi et al. 2002 RCT H) (26). In patients with idiopathic calcium oxalate nephrolithiasis and mild hyperoxaluria (> $40 \mathrm{mg} /$ day), a diet low in protein and salt with normalized calcium intake for the duration of three months proved to be more effective in reducing oxaluria in comparison with a diet low in oxalate administered to a historical control group of hyperoxaluric patients (Nouvenne et al. 2009 observational study L) (27).

\section{Wheat bran}

20. In hypercalciuric renal stone formers the addition of 30 $\mathrm{g}$ of dietary fiber as unprocessed wheat bran to a low-calcium and low-oxalate diet results in a $23.5 \%$ decrease of urinary calcium with respect to the $5.6 \%$ decrease obtained 
with the diet alone whereas the addition of fiber results in a $3.9 \%$ decrease of urinary oxalate compared to the $21.4 \%$ on diet alone (Gleeson 1990 - experimental study - M) (28).

\section{Pyridoxine}

21. The administration of pyridoxine in oral doses of 250$500 \mathrm{mg}$ daily to both normo- or hyperoxaluric calcium renal stone formers decreases urinary oxalate excretion (Nakada 1988 - experimental study - M, Mitwalli 1988 experimental non controlled study M, Ortiz-Alvarado 2010 - experimental non controlled study M) $(18,29,30)$.

\section{Probiotics (Lactobacilli)}

22. The administration of lactobacilli has not proved to be effective in reducing the levels of urinary excretion of oxalate in renal calcium stone patients with idiopathic hyperoxaluria and calcium (> $40 \mathrm{mg}$ /day) (Goldfarb 2007, Lieske 2010 - randomized controlled studies H) (31, 32), in healthy subjects consuming an high-oxalate diet (Siener 2013 - experimental non controlled study M) (33) and in renal stone formers without hyperoxaluria on a diet rich in oxalate (Ferraz 2009 experimental non controlled M) (34).

\section{General measures}

23. Hyperoxaluric patients shows higher lipid intake and lower glucidic and calcium intake (Mahe 1993 observational study VL) (35). Dietary counseling according to Recommended Dietary Allowance results in a reduction of intakes of total protein, animal protein, fat, and carbohydrates and it is associated to a reduction of the excretion of oxalate. (Nomura 1995 - observational study VL) (36). The effect of general dietary measures (balanced diet, specific diet) on urinary oxalate has not always proven effective in reducing urinary oxalate (Kocvara 1999 - controlled study L, Siener 2005 - experimental non randomized M; Schwen 2013 observational study L) (37-39). The dietary approach is particularly recommended after ESWL because it induces an increase of urinary oxalate and calcium (Oehlschläger 2003 - observational study L) (40).

\section{Dietary treatment of hyperuricosuria}

(Martino Marangella, Fabrizio Travaglini, Alberto Trinchieri)

\section{Protein and purine}

1. In patients with renal calcium stones the decrease of the urinary excretion of uric acid after restriction of dietary protein and purine is not well demonstrated. In patients with hyperuricosuria on free diet, the reduction of dietary purine normalized the excretion of uric acid in approximately 45\% of cases (Mateos Anton 1984 - Experimental non controled study L) (1). Complex dietary intervention that included a reduction in protein and purine, such as a diet tailored on metabolic risk factors and a diet based on reduction of animal protein intake (56-64 g/day) and foods high in purine ( $75 \mathrm{mg} /$ day) in combination with an increased intake of fruits, vegetables and cereal grains (including 1/4 cup of bran per day) have not achieved variations of the excretion of uric acid (Kocvara 1999 RCT L, Hiatt 1996 RCT H) (2,3), conversely a standardized balanced diet decreased the excretion of uric acid in others (Siener 2005, experimental study M) (4).

2. A standardized artificial diet (Ensure) in an amount adjusted for the individual caloric needs is not associated with higher levels of uric acid excretion in patients with calcium stones compared with controls (Pais 2007 - experimental study M) (5).

\section{Sodium intake}

3. A diet with a high sodium intake $(240 \mathrm{mEq}$.di sodium for 10 days) to cause an expansion of chronic volume compared to a diet with a low sodium content $(10 \mathrm{mEq}$.di sodium for 10 days) results in increased clearance of acid uric acid, decreased serum uric acid and unchanged uric acid excretion (Breslau and Pak 1984 observational study of good quality M) (6).

\section{Dietary treatment of hypocitraturia}

(Renata Caudarella, Andrea Guttilla, Sebastiano Spatafora)

\section{Introduction}

Hypocitraturia is common metabolic alteration in kidney stone-formers with a prevalence ranging from 20 to $60 \%$; hypocitraturia may be found alone or associated with other metabolic alterations promoting stone formation.

The acid-base status of the patient significantly modulates renal citrate excretion with systemic acidosis promoting citrate absorption in the proximal renal tubule with its subsequent incorporation into the Krebs cycle (1). Instead, alkalosis induces a decrease in citrate absorption, resulting in increased urinary citrate excretion. Conditions associated with a lower value of intracellular and urinary $\mathrm{pH}$, such as metabolic acidosis or hypokalemia, cause a decrease in citrate excretion in urine (2).

Acid-base balance, under physiological conditions, is strictly controlled by the net endogenous acid production related to acid and alkali dietary intake, and the incomplete metabolism of organic acids. The main dietary source of alkali is the conjugate base of potassium salts present in fruits and vegetables whereas the non dairy animal proteins, such as those present in meat, poultry, fish and eggs, which contain amino acids with sulfur moieties, represent the principal intake of dietary acid.

The administration of alkaline-citrates (such as sodium-citrate, potassium citrate, potassium-magnesium citrate, especially potassium citrate) for the medical treatment of stone-formers with hypocitraturia and prevention of stone recurrence is recommended by most international guidelines. Prospective randomized trials exist regarding the treatment of stone recurrence by means of alkali citrate therapy lasting at least 1 year $(3,4)$. The results of these trials seem to suggest that the correction of this metabolic alteration using medical therapy reduces stone risk recurrence. Gastrointestinal side effects are quite common in these patients (approximately 10\%) with a consequent decrease in compliance of up to $25 \%$ (16). The reduced compliance is also due to other factors, such as cost.

\section{Vegetables}

The relationship between a diet rich in vegetables and urinary citrate excretion has also been examined.

Increased intake of fruit and vegetables (excluding those with high oxalate content) increases citrate excretion and consequently decreases urinary saturation for calcium oxalate and calcium phosphate. In fact hypocitraturic subjects have a lower fruit intake (Domrongkitchaiporn et al. 2006, observational study L) (5) and an high consumption of vegetables involves a significant protection against the 
risk of stone formation (Hess et al. 1994, observational study L, Siener et al. 2005, observational non controlled study L, Trinchieri A et al. 2006 and 2013, observational studies L, Meschi et al. 2004, interventional study M) (6-10).

Citrus and non citrus juices

Several authors had studied the possible influence of the consumption of fruit juices (both citrus and non citrus) on urinary citrate excretion. Information on citrate concentrations in citrus juices, non citrus juices and commercially available citrus based beverages are now available (Haleblian et al. 2008) (11).

\section{Lemon juice}

Drinking lemonade or freshly squeezed lemon juice significantly raised urinary citrate levels at least twofold (Seltzer 1996, interventional non controlled M; Aras et al. interventional non randomized $M$; Kang observational $L$ ) (12-14). A decrease in urinary calcium excretion and no changes in urine oxalate levels were also observed. In some studies, the authors were not able to find a significant change in the urinary excretion induced by lemon therapy (Koff, et al 2007 experimental non controlled M) (15) or they found lower increases with respect to potassium citrate or orange juice (Penniston et al 2007 observational L, Odvina et al. experimental non randomized $M)(16,17)$.

\section{Orange juice}

Orange juice consumption resulted in a significantly higher urinary citrate excretion when compared to lemonade. On the contrary urinary oxalate was significantly higher during orange juice consumption, a finding which was not observed with the lemonade consumption.

The saturation ratio of calcium oxalate tended to be lower during orange juice consumption compared with lemonade, but the difference was not significant. (Penniston et al. 2007 observational L: Wabner et al. 1993) (16, 18).

\section{Grapefruit juice}

Grapefruit juice significantly increased urinary citrate and urinary oxalate levels. These events were not associated with an increased risk of supra-saturation of calcium oxalate, calcium phosphate or uric acid. In other words, the increase in oxalate excretion, which would promote lithogenicity, was offset by the increase in citrate excretion (Goldfarb et al. 2001, experimental M) (19).

\section{Lime juice}

In renal stone formers a solution containing lime powder significantly increased urine citrate, potassium, and $\mathrm{pH}$ (Tosukhowong et al. 2008 experimental M) (20).

\section{Non citrus juices}

Cranberry juice had controversial effect on urine citrate (no effect or increase of 31\%), but resulted in a significantly increased concentration of urinary calcium and oxalate (Gettman et al. 2005 experimental non controlled M, McHarg et al. 2003 experimental cross over M) (21, 22).

Unsweetened blackcurrant diluted juice increased urinary citrate by $25 \%$ over baseline (Kessler et al. 2002 experimental M) (23). The consumption of a non citrus alkaline fruit (melon) also has a positive effect in increasing citraturia as compared to citrus fruit consumption (Baia et al. 2012 experimental M) (24).

\section{Other drinks}

In non stone-formers the citrus-based sport drink Performance ${ }^{\circledR}$ increased citrate excretion and urine $\mathrm{pH}$, but the other sport drink Gatorade ${ }^{\circledR}$ did not change either parameter significantly. Thus, Performance ${ }^{\circledR}$ appears to have effects on urine citrate which are similar in magnitude to those observed in some studies using homemade lemonade (Goodman et al. 2009, experimental M) (25).

Consumption of soda showed no significant variations of citrate urinary excretion (Passman et al. 2009 experimental M) (26). Despite the efficacy of these different types of drinks in raising urine citrate, practitioners must be cautious in recommending high volumes of juices or sports beverages for long-term citrate replacement, due to the high caloric content of many preparations that might be associated with unwanted carbohydrate consumption.

\section{Conclusions}

Several patients require modification of their dietary regimen instead of medical treatment as a first option for the prevention of stone recurrence. Both citrus fruits (lemons, oranges, grapefruit, and lime) and non citrus fruits (melon) are natural sources of dietary citrate, and several studies have shown the potential of these fruits and/or their juices in raising urine citrate levels. Nevertheless, future prospective randomized trials having hypocitraturia dietary treatment as the primary endpoint and also comparing pharmacologic therapy with dietary interventions are needed.

\section{Dietary prevention in the child renal stone patient}

Background

Nephrolithiasis in children is most prevalent between 3 and 5 years old, even if it can arise from early childhood to late adolescence. It affects males more frequently than females (1). The most frequent causes of nephrolithiasis in children are urinary tract infections (up to $60 \%$ of cases in some records), metabolic abnormalities (including idiopathic hypercalciuria), congenital urogenital malformations, and cystinuria (2-3). The most frequent composition of stones in children is calcium oxalate (45\%), followed by calcium phosphate (25\%), struvite (17\%) and cystine (8\%), while uric acid stones are very rare (4). Metabolic abnormalities, like hypercalciuria and hypocitraturia, are less prevalent than in adults, although this difference attenuates in adolescents (4). More recent reports however state that their prevalence is rising (5). A complete metabolic evaluation of urinary risk factors is nowadays considered mandatory also in young children (6). Hypercalciuria is traditionally considered the most important urinary risk factor for lithogenesis in children (4, 79), especially in recurrent patients (7). However, recent reports state that hypocitraturia is nowadays the most prevalent risk factor $(8,10)$ and probably the major responsible for kidney stone formation in children (11). A poor hydration is often another fundamental risk factor (12-13). Urinary calcium excretion is generally higher in stone forming children than in healthy age- and sexmatched controls (14). In some cases, hypercalciuria may be caused by excessive vitamin $\mathrm{D}$ intake for rickets pre- 
vention (15-16) or by genetic polymorphisms inducing an abnormal vitamin D metabolism (17).

Hyperoxaluria is the leading metabolic risk factor in about $20 \%$ of pediatric patients (4) and is often geneticallydetermined (primary hyperoxaluria type 1 and 2), although almost half of cases have a dietary origin (18). The relationship between overweight/obesity and nephrolithiasis in children is controversial, with some studies reporting a higher prevalence of hyperoxaluria and hypocitraturia in obese children (19) and others denying any association between body mass index and urinary factors of lithogenic risk (20). There are also data stating that underweight, rather than overweight, is a risk factor for nephrolithiasis in children (21).

\section{Dietary treatment of hypercalciuria in children}

1. Diets with a high calcium content (up to $1 \mathrm{~g} /$ day) are not harmful for urinary calcium excretion, both in stone forming and in control children. Therefore, dietary calcium restriction is not recommended for children with nephrolithiasis. A diet with $1 \mathrm{~g}$ of calcium per day induces a significant $(20 \%)$ rise in urinary calcium excretion lasting only 3 days in stone forming children, compared to a calcium restriction (400 mg/day). After this period, urinary calcium excretion returns to basal levels. Moreover, dietary calcium restriction may promote urinary calcium excretion by inducing a rise in calcitriol levels (22). Moreover, children that are used to a low calcium intake are more sensitive to variations in dietary calcium content (23).

2. Moderate dietary salt restriction and implementation of potassium intake are useful in limiting urinary calcium excretion and thus for primary and secondary prevention of nephrolithiasis. A direct correlation between urinary sodium and urinary calcium excretion and an inverse correlation between urinary potassium and calcium have been demonstrated in children. These correlations are even stronger in adolescents, who are probably more prone to eat large amounts of salty foods and to avoid fruit and vegetables (24). A study carried out on 11 children with idiopathic hypercalciuria has demonstrated that potassium supplementation, through fruit and vegetable intake or potassium citrate ingestion, is associated to a drop in urinary calcium and lithogenic risk (25). Another study, carried out on a small sample of calcium stone formers, found that a diet with a low salt $(1-2 \mathrm{mg} / \mathrm{kg} /$ day $)$ and a high potassium intake $(1 \mathrm{mEq} / \mathrm{kg} /$ day $)$ is able to treat hypercalciuria in virtually all patients (26). However, another study from the same research group found that a low-salt high-potassium protein-balanced diet is effective in resolving hypercalciuria only in 33\% of cases (27). These results have been confirmed by a more recent study, where the above mentioned diet proved to be effective in treating hypercalciuria in only $24 \%$ of 46 hypercalciuric children aged more than 4 (28). The largest study carried out on dietary treatment of hypercalciuric pediatric calcium nephrolithiasis has instead showed that dietary salt restriction alone $(1-2 \mathrm{mg} / \mathrm{kg} /$ day $)$ is effective in reducing calcium excretion in 65 out of 131 (49,6\%) subjects (29). 3. The best therapeutical approach for treating hypercalciuria in children is to prescribe a 3-month period of lowsalt high-potassium diet, followed by personalized pharmacological therapy if hypercalciuria does not resolve.
Almost every study carried out on pediatric hypercalciuria adopted this approach (a 3-month run-in period with dietary therapy followed by a new metabolic evaluation and pharmacologic therapy if metabolic abnormalities do not resolve), which has proven to be very effective (2730 ). This sequential therapeutic schedule is also very effective in preventing kidney stone recurrences on a long-term follow-up (30). The main limitation of these studies is the fact that data are analyzed in an aggregate way, so that the effects of dietary therapy alone are not discernible from that of dietary therapy plus pharmacological intervention.

\section{Dietary treatment of hypocitraturia in children}

4. Hypocitraturia in children is most likely due to a high salt and sugar intake and to a consumption of fruit and vegetables lower than recommended. Like in adult stone formers, also in children salt and sugar intake is inversely correlated with urinary citrate excretion (31). Moreover, hypocitraturic children with kidney stones have low levels of urinary phytate, which is a reliable marker of fruit and vegetable consumption (32). In Western countries, it has been demonstrated that children have an extremely low average intake of vegetables, while the consumption of fruit is slightly increasing in recent years, anyhow lower than recommended (33-34).

5. No studies have assessed the effect of fruit and vegetable supplementation and/or dietary salt and sugar restriction on urinary citrate excretion in pediatric calcium stone formers so far. Therefore, at the moment there is no scientific evidence to recommend this dietary intervention in hypocitraturic children. Even in those studies who have evaluated the possible therapies for pediatric nephrolithiasis in a combined way, hypocitraturia was always treated with pharmacological supplementation with potassium citrate $(27,30)$. This treatment has however proven effective both in raising urinary citrate levels and in diminishing recurrence rates (35).

6. Despite the lack of specific studies, given the wellknown benefits of fruit and vegetable intake, it seems reasonable to advice a balanced consumption of these foods, according to general nutritional guidelines.

\section{Dietary treatment of hyperoxaluria in children}

7. Apart from genetic hyperoxaluria, a high urinary oxalate excretion in children and adolescents is most likely due to a high consuption of oxalate-rich foods such as chocolate and cola. A dietary load of chocolate is able to cause transient hyperoxaluria in adults (36-37). The habitual consumption of cola has also been linked to hyperoxaluria (38). Intake of other oxalate-rich foods does not automatically result in hyperoxaluria, due to lower bioavalaibility (39). It has been demonstrated that children and adolescents have significantly higher intake of chocolate and cola than adults (40-42).

8. No studies have assessed the effects of chocolate and cola restriction on hyperoxaluric pediatric stone formers so far. Therefore, at the moment there is no scientific evidence to recommend this dietary intervention in hyperoxaluric children. All studies that have considered hyperoxaluric pediatric patients have tested dietary interventions combined with pharmacologic approach (vitamin B6), 
demonstrating that this therapy is effective in reducing hyperoxaluria and preventing stone recurrences $(24,30)$. 9. Despite the lack of specific studies, given the wellknown benefits of limiting cola and chocolate intake, it seems reasonable to advice a low consumption of these foods, according to general nutritional guidelines.

Importance of urinary volume in children

10. There are no studies assessing the effectiveness of water therapy alone in the prevention of kidney stone recurrences in pediatric patients. However, given the availability and strength of data in adults, there are sufficient basis to advice an adequate fluid intake also in children. In adults, water therapy alone, as to maintain urinary volume over 2 litres per day, is able to prevent $44 \%$ of recurrences in patients with a first episode of renal colic (43). No data are available for children, but all studies carried out on pediatric nephrolithiasis have prescribed an adequate fluid intake in addition to dietary and pharmacological treatments. These recommendation may be crucial in pediatric subjects where no metabolic abnormalities are present (12-13).

Diet for the obese children with kidney stones

11. No studies have assessed specific dietary treatments to prevent nephrolithiasis in obese children. Therefore, in this category of patients, it seems reasonable to recommend the usual diets for childhood obesity.

Dietary treatment in children with cystinuria

12. Despite the low level of scientific evidence, a low-protein $(<20 \mathrm{~g} /$ day) low-salt $(<2 \mathrm{~g}$ /day) diet with high hydration ( $>3$ litres/day) is strongly advised in children with cystinuria.In a study carried out on one patient with cystinuria many years ago, a $20 \mathrm{~g}$ /day protein intake proved to reduce basal cysteine levels by $31 \%$ compared with a $117 \mathrm{~g} /$ day protein intake (44). It is probable that cystine excretion is strongly influenced also by the specific type of proteins of foods. A diet with a high glutamine but with normal overall protein intake is actually able to diminish cystine excretion (45). However, this dietary manipulation is effective only when salt intake is liberal (46). Salt restriction itself is highly effective in diminishing cystine excretion, provided that it is very strict $(<2 \mathrm{~g} /$ day $)$ (46-47). In a study carried out on 5 patients, a salt intake $<2 \mathrm{~g} /$ day has been associated to a $50 \%$ reduction in urinary cystine (47). However, such a strict salt restriction is very difficult to achieve and maintain in Western countries.

Dietary therapy in cystinuria has only a supportive role 13. Low-protein low-salt high-fluid diet alone is poorly effective in preventing kidney stone recurrences in cystinuria. Association with urinary alkalinization and pharmacological treatment with thiola is often mandatory to achieve an acceptable prevention (48).

Final considerations and conclusions

High- or fair-quality intervention studies on dietary treatment of pediatric nephrolithiasis are lacking. Available studies have in fact several important limitations, including: Low number of patients; Poor characterization of the precise diagnosis of patients (i.e., idiopathic calcium nephrolithiasis vs secondary calcium nephrolithiasis vs asymptomatic crystalluria); Poor characterization of meta- bolic phenotype; No stratification of data and results for metabolic phenotype; Multiple treatments (dietary interventions are often studied together with drug therapy); Lack of stratification for age groups (some studies consider together patients younger than 2 years old and adolescents); Poor characterization of basal dietary habits; Poor definition of outcomes; Short term follow-ups.

Moreover, some of these studies were carried out many years ago, and thus did not take into account epidemiologic changes that occurred in the last decade(s).

Therefore, it is not possible to express any high- or fairlevel recommendation on dietary therapy in pediatric nephrolithiasis. All advices reported above are thus relying on poor-quality data or on expert opinion.

\section{Dietary prevention in the elderly renal stone patient}

\section{Background}

Definition of elderly patient: The chronological age of 65 years as a definition of 'elderly' patient has conventionally been accepted. However, this convention is not exhaustive and is rather restrictive, not taking into account the large inter-individual biological variability within the same chronological age. Therefore it would be more appropriate to take into consideration some parameters referring to biological aging, as regressive change of the structure and the function of different organs and systems of the human body. The elderly, however defined, has a lower functional reserve and increased fragility compared to the young (1-2). Therefore during the biological process of aging changes of the body occur that affect clinical and diagnostic aspect in the elderly.

Epidemiology of nephrolithiasis in the elderly: In the case series reported by various studies on nephrolithiasis, 10$12 \%$ (3-4) of the patients with urinary stones are over 65 years. However, in the general population over the age of 65 , it has been shown a ratio of stone formation ranging $0.1-2 \%$, that is not higher compared to that found in the younger population (5-6). An increase of crystalluria, which is known to represent a potential early stage of lithiasis, has also been described in the urine of elderly subjects (7). In the elderly recurrence and severity of the stone disease is the same than in the general population (4).

Stone composition and metabolic aspects of nephrolithiasis in the elderly: Before dealing with the presence of metabolic risk factors for stone formation in the elderly population, it has to be pointed out that the average level of renal function in the elderly is reduced compared to younger patients. This aspect by itself may contribute to metabolic changes in the older patient with nephrolithiasis. For example, it is known that there is a reduction of calcium excretion in relation to the decrease of glomerular filtration and associated to a reduced intestinal absorption of this mineral. Well-known alterations of bone metabolism and intermediary metabolism can influence both some typical parameters of mineral metabolism (PTH, calcium, phosphorus) and of intermediary metabolism (uric acid). Moreover, it has to be pointed out that the style of life, in particular for what concerns the food habits, is changed significantly with increasing age.

Accordingly, the larger series show that calcium oxalate 
stones are the more frequent also in elderly patients as in the general population but the rate of uric acid stones is greater in the elderly $(4,8,9)$. Some studies show that about $10-20 \%$ of patients suffering from gout form uric acid stones and conversely that $40 \%$ of patients with uric acid stones develop gout $(10,11)$. About $50 \%$ of elderly people suffering from kidney stones show an isolated metabolic defect in 24 hour urine (12). The most frequent is hypocitraturia with a rate in stone patients from $29 \%$ to $56 \%(4,13)$. This figure would seem correlated to a physiological metabolic acidosis related to the progressive decrease of renal function with age. A urine $\mathrm{pH}$ below 5.5 promotes uric acid stone formation more than hyperuricosuria or hyperuricemia (10). In elderly people suffering from kidney stones, the values of PTH are significantly increased and the values of 1,25-hydroxyvitamin D reduced (4). Furthermore, especially in the elderly patients on long-term care, lower levels of natural vitamin D were found $(14,15)$. Metabolic abnormalities are equally represented in both sexes in the elderly. In addition to the different prevalence of some metabolic disorders, other factors that are potentially lithogenic, could contribute to renal stone formation in the elderly. Among these factors, infections of the urinary tract and reduced mobility could play a major role. In fact infections of the urinary tract are common in the elderly. However, although some studies show that in the elderly there is an increased risk of urinary tract infection, such data are not correlated to an higher rate of infection stones, that account for only $1 \%$ in the elderly (4-8). The reduction of ambulation in the elderly could cause an increased excretion of calcium in the urine. However, this condition is described only after prolonged periods of immobilization.

\section{Diet}

Dietary counseling for renal stone prevention in the elderly has to consider some particular aspects of aging.

1. About sodium intake, it is well known that diets high in sodium expose renal stone patients, especially if overweight and hypercalciuric, to an increase in urinary calcium excretion (Taylor 2006 prospective study, evidence L) (16) which may increase the lithogenic risk and the risk to develop hypertension and bone demineralization.

However, it should be considered that the elderly patient is particularly sensitive to sodium intake from a hemodynamic point of view. Consequently, effects of any other concomitant therapy have to be attentively considered in relation to this aspect.

2. It is also known that a diet with a higher content of potassium, magnesium and citrate, is particularly effective not only in reducing the incidence of urinary risk factors for stone formation (hypercalciuria, hypocitraturia) but also in preventing the loss of bone mass and the incidence of arterial hypertension (Ettinger 1997 prospective study, evidence L) (17). There are no particular additional problems in recommending such a diet in the older patient.

3. An important aspect to be considered is the calcium content in the diet. In the past, patients with calcium nephrolithiasis were given advice to avoid foods with an high calcium content. In recent decades more data have accumulated showing that a diet with a normal calcium content, but with reduced intake of animal protein (Taylor,
2009, prospective, evidence L) (18) would be more protective on the lithogenic risk compared to a diet with reduced intake of calcium and oxalate, in particular in subjects with hypercalciuria. In fact, the reduced availability of calcium in the intestine would favor the increase of intestinal absorption of oxalate (Messa, 1997 prospective study, evidence L) (19). Moreover, a low-calcium diet expose patients to an increased risk of osteoporosis. This risk is certainly higher in the elderly, especially if female. There is no general indication in the renal stone patient to a low-calcium diet and even less in the elderly. Therefore a diet rich in calcium (1200 mg/day) would be useful for the proper maintenance of both the musculoskeletal wellness and the prevention of kidney stones. In contrast a further supplementation could involve an increase of risk for both the formation of kidney stones and cardiovascular diseases (20).

4. Diets high in animal protein have been recognized to increase the risk of stone formation, probably by increasing the acid load (which reduces the excretion of citrate and rises calcium excretion secondary to increased removal from the bone) and the production and excretion of uric acid. Although there are no prospective randomized studies that provide clear evidence of its clinical effects on prevention of renal stone disease and hypertension, some observational studies suggest that the adoption of a low-sodium diet, with increased intake of fruits and vegetables and reduced fat intake can be effective in the prevention of nephrolithiasis (Taylor, 2009, prospective, evidence L) (18). In any case, a diet with lower content of animal protein and higher intake of plant products has no particular contraindications in the elderly patient with nephrolithiasis, although overall nutritional status of such patients must be always evaluated with great attention.

5. The available information about the usefulness of the reduction in the content of dietary oxalate is poor (Taylor, 2007 , prospective, evidence L) (21). Therefore, in the elderly, it remains a questionable.

In renal stone patients with high disease activity, when diet is not effective, use of drugs and dietary supplements (thiazide diuretics, allopurinol, citrate salts, etc.) is often advisable. There are no differences in prescribing pharmacological treatment in the elderly with respect to younger renal stone patients, although greater caution should be maintained in the use of diuretics (Sonnenblick, 1993 observational study, evidence L) (22) for the obvious hemodynamic reasons and the greater frequency of decreased renal function in this range of age. In the case of elderly patients with nephrolithiasis on therapy with inhibitors of the renin-angiotensin-aldosterone system, attention should also be taken in the use of potassium citrate salts.

\section{REFERENCES \\ Introduction}

1. Romero V, Akpinar H, Assimos DG. Kidney stones: a global picture of prevalence, incidence, and associated risk factors. Rev Urol. 2010; 12:86-96.

2. Sakhaee K, Maalouf NM, Sinnott B. Clinical review. Kidney stones 2012: pathogenesis, diagnosis, and management. J Clin Endocrinol Metab. 2012; 97:1847-1860.

3. Worcester EM, Coe FL. Clinical practice. Calcium kidney stones. N Engl J Med. 2010; 363:954-963. 
4. Coe FL, Evan A, Worcester E. Kidney stone disease. J Clin Invest. 2005; 115:2598-2608.

5. Lotan Y. Economics and cost of care of stone disease. Adv Chronic Kidney Dis. 2009; 16:5-10.

6. Shoag J, Halpern J, Goldfarb DS, Eisner BH. Risk of chronic and end stage kidney disease in patients with nephrolithiasis. J Urol. 2014; 192:1440-5

7. Worcester EM, Coe FL. Nephrolithiasis. Prim Care 2008; 35:369-391.

8. Turney BW, Appleby PN, Reynard JM, Net al. Diet and risk of kidney stones in the Oxford cohort of the European Prospective Investigation into Cancer and Nutrition (EPIC). Eur J Epidemiol. 2014; 29:363-9.

9. Rendina D, De Filippo G, De Pascale F, et al. The changing profile of patients with calcium nephrolithiasis and the ascendancy of overweight and obesity: a comparison of two patient series observed 25 years apart. Nephrol Dial Transplant. 2013; 28 Suppl 4:iv146-51.

10. Rendina D, De Filippo G, D'Elia L, Strazzullo P. Metabolic syndrome and nephrolithiasis: a systematic review and meta-analysis of the scientific evidence. J Nephrol. 2014 Apr 3.

11. Wiederkehr MR, Moe OW. Uric Acid Nephrolithiasis: A Systemic Metabolic Disorder. Clin Rev Bone Miner Metab. 2011; 9:207-217.

12. Cupisti A. Update on nephrolithiasis: beyond symptomatic urinary tract obstruction. J Nephrol. 2011; 24 Suppl 18:S25-9.

13. Sakhaee K. Nephrolithiasis as a systemic disorder. Curr Opin Nephrol Hypertens. 2008; 17:304-9.

14. Percorso diagnostico-terapeutico per il paziente con calcolosi urinaria. Gruppo di Studio Multidisciplinare per la Calcolosi Renale. Giornale Italiano di Nefrologia 2010; 27:282-289.

15. Pearle MS, Goldfarb DS, Assimos DG, et al. American Urological Assocation. Medical management of kidney stones: AUA guideline. J Urol. 2014; 192:316-24.

16. Pak CY, Heller HJ, Pearle MS, et al. Prevention of stone formation and bone loss in absorptive hypercalciuria by combined dietary and pharmacological interventions. J Urol. 2003; 169:465-9.

17. Kourambas J, Aslan P, Teh CL, et al. Role of stone analysis in metabolic evaluation and medical treatment of nephrolithiasis. Endourol. 2001; 15: 181-6.

18. Ramakumar S, Patterson DE, LeRoy AJ, et al: Prediction of stone composition from plain radiographs: a prospective study. J Endourol 1999; 13:397-401.

19. Mandel N, Mandel I, Fryjoff K, et al. Conversion of calcium oxalate to calcium phosphate with recurrent stone episodes. J Urol. 2003; 169:2026-9.

20. Badereddin Mohamad Al-Ali, Johanna Patzak, Herbert Augustin. Impact of urinary stone volume on computed tomography stone attenuations measured in Hounsfield units in a large group of Austrian patients with urolithiasis. Cent European J Urol. 2014; 67:289-95.

21. Hesse A, Kruse R, Geilenkeuser WJ, et al. Quality control in urinary stone analysis: results of 44 ring trials (1980-2001). ClinChem Lab Med. 2005; 43:298-303.

22. Suror DJ, Scheidt S. Identification standards for human urinary calculus components, using crystallographic methods. Br J Urol. 1968; 40:22-8.

23. Abdel-Halim RE, Abdel-Halim MR. A review of urinary stone analysis techniques. Saudi Med J. 2006; 27:1462-7.

24. Kasidas GP, Samuell CT, Weir TB. Renal stone analysis: why and how? Ann.Clin.Biochem. 2004; 41:91-7.

25. Douglas DE, Tonks DB. The qualitative analysis of renal calculi with the polarising microscope. ClinBiochem. 1979; 12:182-3.

26. Abbas Basiri, Maryam Taheri, FatemehTaheri. What is the State of the Stone Analysis Techniques in Urolithiasis? Urology Journal 2012; 9:445-454.
27. Hidas $G$, Eliahou R, Duvdevani M, et al. Determination of renal stone composition with dual-energy CT: in vivo analysis and comparison with x-ray diffraction. Radiology. 2010; 257:394-401.

28. Borghi L, Meschi T, Schianchi T, et al: Urine volume: Stone risk factor and preventive measure. Nephron 1999; 81 (suppl 1):31-37.

29. Pak CYC, Sakhaee K, Crowther C \& Brinkley L. Evidence justifying a high fluid intake in treatment of nephrolithiasis. Ann. Intern. Med. 1980; 93:36-39.

30. Borghi L, Meschi T, Amato F, et al: Urinary volume, water and recurrences in idiopathic calcium nephrolithiasis: a 5-year randomized prospective study. J Urol. 1996; 155:839.

31. Sarica K, Inal Y, Erturhan S, Yagci F. The effect of calcium channel blockers on stone regrowth and recurrence after shock wave lithotripsy. Urol Res. 2006; 34:184-9.

32. Frank M, De Vries A, Tikva P. Prevention of urolithiasis. Education to adequate fluid intake in a new town situated in the Judean Desert Mountains. Archives of Environmental Health. 1966; 13:625-30.

33. Curhan GC, Willett WC, Rimm EB, Stampfer MJ. A prospective study of dietary calcium and other nutrients and the risk of symptomatic kidney stones. New England Journal of Medicine 1993; 328:833-8.

34. Coen G, Sardella D, Barbera G, et al. Urinary composition and lithogenic risk in normal subjects following oligomineral versus bicarbonate-alkaline high calcium mineral water intake. Urol Int. 2001; 67:49-53.

35. Gutenbrunner C, Gilsdorf K, Hildebrandt G. The effect of mineral water containing calcium on supersaturation of urine with calcium oxalate. Urologe A. 1989; 28:15-19.

36. Rodgers AL. The influence of South African mineral water on reduction of risk of calcium oxalate kidney stone formation. S AfrMed J. 1998; 88:448-451.

37. Trinchieri A, Boccafoschi C, Chisena S, et al. Study of the diuretic efficacy and tolerability of therapy with Rocchetta mineral water in patients with recurrent calcium kidney stones. Arch Ital Urol Androl. 1999; 71:121-124.

38. Karagülle O, Smorag U, Candir F, et al. Clinical study on the eVect of mineral waters containing bicarbonate on the risk of urinary stone formation in patients with multiple episodes of CaOx-urolithiasis World J Urol. 2007; 25:315-323.

39. Bertaccini A, Borghesi M. Indications for a medium mineral high bicarbonate water (Cerelia) in urology. Arch Ital Urol Androl. 2009; 81:192-4.

40. Siener R, Jahnen A, Hesse A Influence of a mineral water rich in calcium, magnesium and bicarbonate on urine composition and the risk of calcium oxalate crystallization. European Journal of Clinical Nutrition. 2004; 58, 270-276.

\section{Diet and hypercalciuria}

1. Escribano J, Balaguer A, Roqué i Figuls M, et al. Dietary interventions for preventing complications in idiopathic hypercalciuria. The Cochrane Library 2014, Issue 2.

2. Nishiura JL, Campos AH, Boim MA, et al. Phyllanthus niruri normalizes elevated urinary calcium levels in calcium stone forming (CSF) patients. Urological Research 2004; 32:362-6.

3. Coe FL, Parks JH, Webb DR. Stone-forming potential of milk or calcium-fortified orange juice in idiopathic hypercalciuric adults. Kidney International 1992; 41: 139-42.

4. Taylor EN, Curhan GC. Demographic, dietary, and urinary factors and 24-h urinary calcium excretion. Clin J Am Soc Nephrol. 2009; 4:1980-7.

5. Curhan GC, Willett WC, Rimm EB, Stampfer MJ. A prospective study of dietary calcium and other nutrients and the risk of symptomatic kidney stones. N Engl J Med. 1993; 328:833-8. 
6. Pak CY, Odvina CV, Pearle MS, et al. Effect of dietary modification on urinary stone risk factors. Kidney Int. 2005; 68:2264-73.

7. Damasio B, Massarino F, Durand F, et al. Prevalence of fasting hypercalciuria associated with increased citraturia in the ambulatory evaluation of nephrolithiasis. J Nephrol. 2005; 18:262-6.

8. Burtis WJ, Gay L, Insogna KL, et al. Dietary hypercalciuria in patients with calcium oxalate kidney stones. Am J Clin Nutr. 1994; 60:424-9.

9. Jaeger P, Portmann L, Jacquet AF, Burckhardt P. Influence of the calcium content of the diet on the incidence of mild hyperoxaluria in idiopathic renal stone formers. Am J Nephrol. 1985; 5:40-4.

10. Nishiura JL, Martini LA, Mendonça CO, et al. Effect of calcium intake on urinary oxalate excretion in calcium stone-forming patients. Braz J Med Biol Res. 2002; 35:669-75.

11. Heilberg IP, Martini LA, Draibe SA, et al. Sensitivity to calcium intake in calcium stone forming patients. Nephron. 1996; 73:145-53.

12. Nakada T, Sasagawa I, Furuta H, et al. Effect of high-calcium diet on urinary oxalate excretion in urinary stone formers. Eur Urol. 1988; 15:264-70.

13. van Faassen A, van der Ploeg EM, Habets HM, et al. The effects of the calcium-restricted diet of urolithiasis patients with absorptive hypercalciuria type II on risk factors for kidney stones and osteopenia. Urol Res. 1998; 26:65-9.

14. Messa P, Marangella M, Paganin L, et al. Different dietary calcium intake and relative supersaturation of calcium oxalate in the urine of patients forming renal stones. Clin Sci. 1997; 93:257-63.

15. Bataille P, Pruna A, Grégoire I, et al. Critical role of oxalate restriction in association with calcium restriction to decrease the probability of being a stone former: insufficient effect in idiopathic hypercalciuria. Nephron. 1985; 39:321-4.

16. Borghi L, Schianchi T, Meschi T, et al. Comparison of two diets for the prevention of recurrent stones in idiopathic hypercalciuria. N Engl J Med. 2002; 346:77-84.

17. Nouvenne A, Meschi T, Prati B, et al. Effects of a low-salt diet on idiopathic hypercalciuria in calcium-oxalate stone formers: a 3-mo randomized controlled trial. Am J Clin Nutr. 2010; 91:565-70.

18. Giannini S, Nobile M, Sartori L, et al. Acute effects of moderate dietary protein restriction in patients with idiopathic hypercalciuria and calcium nephrolithiasis. Am J Clin Nutr. 1999; 69:267-71.

19. Taylor EN, Stampfer MJ, Curhan GC. Fatty acid intake and incident nephrolithiasis. Am J Kidney Dis. 2005; 45:267-74.

20. Rothwell PJ, Green R, Blacklock NJ, Kavanagh JP. Does fish oil benefit stone formers? J Urol. 1993; 150:1391-4.

21. Ortiz-Alvarado O, Miyaoka R, Kriedberg C, et al. Omega-3 fatty acids eicosapentaenoic acid and docosahexaenoic acid in the management of hypercalciuric stone formers. Urology. 2012; 79:282-6.

22. Yasui T, Tanaka H, Fujita K, et al. Effects of eicosapentaenoic acid on urinary calcium excretion in calcium stone formers. Eur Urol. 2001; 39:580-5

23. Ohkawa T, Ebisuno S, Kitagawa M, et al. Rice bran treatment for patients with hypercalciuric stones: experimental and clinical studies. J Urol. 1984; 132:1140-5.

24. Strohmaier WL, Kalchthaler M, Bichler KH. Calcium metabolism in normal and in hypercalciuric patients on Farnolith, a dietary fibre preparation. Urol Res. 1988; 16:437-40.

25. Tizzani A, Casetta G, Piana P, Vercelli D. Wheat bran in the selective therapy of absorptive hypercalciuria: a study performed on 18 lithiasic patients. J Urol. 1989; 142:1018-20.

26. Gleeson MJ, Thompson AS, Mehta S, Griffith DP. Effect of unprocessed wheat bran on calciuria and oxaluria in patients with urolithiasis. Urology. 1990; 35:231-4.

27. Sweeney DD, Tomaszewski JJ, Ricchiuti DD, Averch TD. Effect of carbohydrate-electrolyte sports beverages on urinary stone risk factors. J Urol. 2009; 182:992-7.

\section{Diet and hyperoxaluria}

1. Zimmermann DJ, Hesse A, von Unruh GE. Influence of a highoxalate diet on intestinal oxalate absorption. World J Urol. 2005; 23:324-9.

2. Butz M, Hoffmann H, Kohlbecker G. Dietary influence on serum and urinary oxalate in healthy subjects and oxalate stone formers. Urol Int. 1980; 35:309-1514.

3. Siener R, Ebert D, Nicolay C, Hesse A. Dietary risk factors for hyperoxaluria in calcium oxalate stone formers. Kidney Int. 2003; 63:1037-43

4. Massey LK, Sutton RA. Modification of dietary oxalate and calcium reduces urinary oxalate in hyperoxaluric patients with kidney stones. J Am Diet Assoc. 1993; 93:1305-7.

5. Kirac M, Küpeli B, Irkilata L, et al. Effects of dietary interventions on 24-hour urine parameters in patients with idiopathic recurrent calcium oxalate stones. Kaohsiung J Med Sci. 2013; 29:88-92.

6. Kırac M, Küpeli B, Irkilata L, et al. Effects of dietary interventions on 24-hour urine parameters in patients with idiopathic recurrent calcium oxalate stones. Kaohsiung J Med Sci. 2013; 29:88-92.

7. Laminski NA, Meyers AM, Kruger M, et al. Hyperoxaluria in patients with recurrent calcium oxalate calculi: dietary and other risk factors. Br J Urol. 1991; 68:454-8.

8. Griffith HM, O'Shea B, Maguire M, et al. A case-control study of dietary intake of renal stone patients. II. Urine biochemistry and stone analysis. Urol Res. 1986; 14:75-82.

9. Peña de la Vega L, Lieske JC, Milliner D, et al. Urinary oxalate excretion increases in home parenteral nutrition patients on a higher intravenous ascorbic acid dose. JPEN J Parenter Enteral Nutr. 2004; $28: 435-8$.

10. Massey LK, Liebman M, Kynast-Gales SA. Ascorbate increases human oxaluria and kidney stone risk. J Nutr. 2005; 135:1673-7.

11. Eisner BH, Sheth S, Dretler SP, et al. High dietary magnesium intake decreases hyperoxaluria in patients with nephrolithiasis. Urology. 2012; 80:780-3.

12. Trinchieri A, Ostini F, Nespoli R, et al. Hyperoxaluria in patients with idiopathic calcium nephrolithiasis. J Nephrol. 1998; 11 Suppl 1:70-2.

13. von Unruh GE, Voss S, Sauerbruch T, Hesse A. Reference range for gastrointestinal oxalate absorption measured with a standardized [13C2] oxalate absorption test. J Urol. 2003; 169:687-90.

14. von Unruh GE, Voss S, Sauerbruch T, Hesse A. Dependence of oxalate absorption on the daily calcium intake. J Am Soc Nephrol. 2004; 15:1567-73.

15. Bataille P, Pruna A, Gregoire I, et al. Critical role of oxalate restriction in association with calcium restriction to decrease the probability of being a stone former: insufficient effect in idiopathic hypercalciuria. Proc Eur Dial Transplant Assoc. 1983; 20:401-6.

16. Jaeger P, Portmann L, Jacquet AF, Burckhardt P. Influence of the calcium content of the diet on the incidence of mild hyperoxaluria in idiopathic renal stone formers. Am J Nephrol. 1985; 5:40-4.

17. Brown JM, Stratmann G, Cowley DM, et al. The variability and dietary dependence of urinary oxalate excretion in recurrent calcium stone formers. Ann Clin Biochem. 1987; 24:385-90.

18. Nakada T, Sasagawa I, Furuta H, et al. Effect of high-calcium diet on urinary oxalate excretion in urinary stone formers. Eur Urol. 1988; 15:264-70.

19. Penniston KL, Nakada SY. Effect of dietary changes on urinary oxalate excretion and calcium oxalate supersaturation in patients with hyperoxaluric stone formation. Urology. 2009; 73:484-9. 
20. Marangella $M$, Bianco $O$, Martini $C$, et al. Effect of animal and vegetable protein intake on oxalate excretion in idiopathic calcium stone disease. Br J Urol. 1989; 63:348-51.

21. Siener $R$, Hesse A. The effect of different diets on urine composition and the risk of calcium oxalate crystallisation in healthy subjects. Eur Urol. 2002; 42:289-96.

22. Noori N, Honarkar E, Goldfarb DS, et al. Urinary lithogenic risk profile in recurrent stone formers with hyperoxaluria: a randomized controlled trial comparing DASH (Dietary Approaches to Stop Hypertension)-style and low-oxalate diets. Am J Kidney Dis. 2014; 63:456-63

23. Meschi T, Maggiore U, Fiaccadori E, et al. The effect of fruits and vegetables on urinary stone risk factors. Kidney Int. 2004; 66:2402-10.

24. Nguyen QV, Kälin A, Drouve U, Casez JP, Jaeger P. Sensitivity to meat protein intake and hyperoxaluria in idiopathic calcium stone formers. Kidney Int. 2001; 59:2273-81.

25. Giannini S, Nobile M, Sartori L, et al. Acute effects of moderate dietary protein restriction in patients with idiopathic hypercalciuria and calcium nephrolithiasis. Am J Clin Nutr. 1999; 69:267-71.

26. Borghi L, Schianchi T, Meschi T, et al. Comparison of two diets for the prevention of recurrent stones in idiopathic hypercalciuria. N Engl J Med. 2002; 346:77-84.

27. Nouvenne A, Meschi T, Guerra A, et al. Diet to reduce mild hyperoxaluria in patients with idiopathic calcium oxalate stone formation: a pilot study. Urology. 2009; 73:725-30.

28. Gleeson MJ, Thompson AS, Mehta S, Griffith DP. Effect of unprocessed wheat bran on calciuria and oxaluria in patients with urolithiasis. Urology. 1990; 35:231-4.

29. Mitwalli A, Ayiomamitis A, Grass L, Oreopoulos DG. Control of hyperoxaluria with large doses of pyridoxine in patients with kidney stones. Int Urol Nephrol. 1988; 20:353-9.

30. Ortiz-Alvarado O, Miyaoka R, Kriedberg C, et al. Pyridoxine and dietary counseling for the management of idiopathic hyperoxaluria in stone-forming patients. Urology. 2011; 77:1054-8.

31. Goldfarb DS, Modersitzki F, Asplin JR. A randomized, controlled trial of lactic acid bacteria for idiopathic hyperoxaluria. Clin J Am Soc Nephrol. 2007; 2:745-9.

32. Lieske JC, Tremaine WJ, De Simone C, et al. Diet, but not oral probiotics, effectively reduces urinary oxalate excretion and calcium oxalate supersaturation. Kidney Int. 2010; 78:1178-85.

33. Siener R, Bade DJ, Hesse A, Hoppe B. Dietary hyperoxaluria is not reduced by treatment with lactic acid bacteria. J Transl Med. 2013; 12; 11:306.

34. Ferraz RR, Marques NC, Froeder L, et al. Effects of Lactobacillus casei and Bifidobacterium breve on urinary oxalate excretion in nephrolithiasis patients. Urol Res. 2009; 37:95-100.

35. Mahe JL, Cledes J, Bigot JC, et al. Results of dietary evaluation during calcium oxalate and calcium phosphate lithiasis. Nephrologie. 1993; 14:291-7.

36. Nomura K1, Ito H, Masai M, et al. Reduction of urinary stone recurrence by dietary counseling after SWL. J Endourol. 1995; 9:305-12.

37. Kocvara R, Plasgura P, Petrík A, et al. A prospective study of nonmedical prophylaxis after a first kidney stone. BJU Int. 1999; 84:393-8

38. Siener R, Schade N, Nicolay C, et al. The efficacy of dietary intervention on urinary risk factors for stone formation in recurrent calcium oxalate stone patients. J Urol. 2005; 173:1601-5.

39. Schwen ZR, Riley JM, Shilo Y, Averch TD. Dietary management of idiopathic hyperoxaluria and the influence of patient characteristics and compliance. Urology. 2013; 82:1220-5.

40. Oehlschläger S, Albrecht S, Hakenberg OW, et al. Early changes of oxalate and calcium urine excretion in those with calcium oxalate stone formation after extracorporeal shock wave lithotripsy. Urology. 2003; 62:17-21.

\section{Diet and hypocitraturia}

1. Zuckerman JM, Assimos DG. Hypocitraturia: pathophysiology and medical management. Rev. Urol. 2009; 11:134-144.

2. Caudarella R, Vescini F, Buffa A, et al Citrate and mineral metabolism: kidney stones and bone disease Front Biosci. 2003; 1;8:s1084-106.

3. Ettinger B, Pak CY, Citron JT, et al. Potassium-magnesium citrate is an effective prophylaxis against recurrent calcium oxalate nephrolithiasis. J Urol. 1997; 158:2069-2073.

4. Barcelo P, Wuhl O, Servitge E, et al. Randomised double-blind study of potassium citrate in idiopathic hypocitraturic calcium nephrolithiasis. J Urol.1993; 150:1761-1764.

5. Domrongkitchaiporn S, Stitchantrakul W, Kochakarn W. Causes of hypocitraturia in recurrent calcium stone formers: focusing on urinary potassium excretion. Am J Kidney Dis. 2006; 48:546-54.

6. Hess B, Michel R, Takkinen R, et al. Risk factors for low urinary citrate in calcium nephrolithiasis: low vegetable fibre intake and low urine volume to be added to the list. Nephrol Dial Transplant. 1994; 9:642-9

7. Siener R, Schade N, Nicolay C, et al. The efficacy of dietary intervention on urinary risk factors for stone formation in recurrent calcium oxalate stone patients. J Urol. 2005; 173:1601-5.

8. Trinchieri A, Lizzano R, Marchesotti F, Zanetti G. Effect of potential renal acid load of foods on urinary citrate excretion in calcium renal stone formers. Urol Res. 2006; 34:1-7.

9. Trinchieri A, Maletta A, Lizzano R, Marchesotti F. Potential renal acid load and the risk of renal stone formation in a case-control study.Eur J Clin Nutr. 2013; 67:1077-80.

10. Meschi T, Maggiore U, Fiaccadori E, et al. The effect of fruits and vegetables on urinary stone risk factors. Kidney Int. 2004; 66:2402-10.

11. Haleblian GE, Leitao VA, Pierre SA, et al. Assessment of citrate concentrations in citrus fruit-based juices and beverages: implications for management of hypocitraturic nephrolithiasis. J. Endourol. 2008; 22:1359-1366.

12. Seltzer MA, Low RK, McDonald M, et al. Dietary manipulation with lemonade to treat hypocitraturic calcium nephrolithiasis. J Urol. 1996; 156:907-909

13. Aras B, Kalfazade N, Tugcu V, et al. Can lemon juice be an alternative to potassium citrate in the treatment of urinary calcium stones in patients with hypocitraturia? A prospective randomized study. Urol Res. 2008; 36:313-7.

14. Kang DE, Sur RL, Haleblian GE, et al. Long-term lemonade based dietary manipulation in patients with hypocitraturic nephrolithiasis. $J$ Urol. 2007; 177:1358-1362

15. Koff SG, Paquette EL, Cullen J, et al. Comparison between lemonade and potassium citrate and impact on urine $\mathrm{pH}$ and 24-hour urine parameters in patients with kidney stone formation. Urology. 2007; 69:1013-1016.

16. Penniston KL, Steele, TH, Nakada SY. Lemonade therapy increases urinary citrate and urine volumes in patients with recurrent calcium oxalate stone formation. Urology. 2007; 70:856-860.

17. Odvina CV. Comparative value of orange juice versus lemonade in reducing stone-forming risk. Clin J Am Soc Nephrol. 2006; 1:12691274.

18. Wabner CL, Pak CY. Effect of orange juice consumption on urinary stone risk factors. J Urol. 1993; 149:1405-1408.

19. Goldfarb DS, Asplin JR. Effect of grapefruit juice on urinary lithogenicity. J Urol. 2001; 166:263-267. 
20. Tosukhowong P, Yachantha C, Sasivongsbhakdi T, et al. Citraturic, alkalinizing and antioxidative effects of limeade-based regimen in nephrolithiasis patients. Urol Res. 2008; 36:149-155.

21. Gettman MT, Ogan K, Brinkley LJ, et al. Effect of cranberry juice consumption on urinary stone risk factors. J Urol. 2005; 174:590-4.

22. McHarg T, Rodgers A, Charlton K. Influence of cranberry juice on the urinary risk factors for calcium oxalate kidney stone formation. BJU Int. 2003; 92:765-768.

23. Kessler T, Jansen B, Hesse A. Effect of blackcurrant-, cranberryand plum juice consumption on risk factors associated with kidney stone formation. Eur J Clin Nutr. 2002; 56:1020-1023.

24. Baia Lda C, Baxmann AC, Moreira SR, et al. Noncitrus alkaline fruit: a dietary alternative for the treatment of hypocitraturic stone formers. J Endourol. 2012; 26:1221-1226.

25. Goodman JW, Asplin JR, Goldfarb DS. Effect of two sports drinks on urinary lithogenicity. Urol Res. 2009; 37:41-46.

26. Passman CM, Holmes RP, Knight J, et al. Effect of soda consumption on urinary stone risk parameters. J Endourol. 2009; 23:347-350.

\section{Dietary prevention in children}

1. Van't Hoff WG. Aetiological factors in pediatric urolithiasis. Nephron Clin Pract 2004; 98:c45-c48.

2. Gearhart JP, Herzberg GZ, Jeffs RD. Childhood urolithiasis: experiences and advances. Pediatrics 1991; 87:445-450.

3. Diamond DA. Clinical patterns of paediatric urolithiasis. Brit J Urol. 1991; 68:195-198.

4. Milliner DS, Murphy ME. Urolithiasis in pediatric patients. Mayo Clin Proc. 1993; 68:241-248.

5. Coward RJM, Peters CJ, Duffy PG, et al. Epidemiology of paediatric renal stone disease in the UK. Arch Dis Child. 2003; 88:962-965.

6. Drach GW. Metabolic evaluation of pediatric patients with stones. Urol Clin N Am. 1995; 22:95-100.

7. DeFoor WR, Jackson E, Minevich E, et al. The risk of recurrent urolithiasis in children is dependent on urinary calcium and citrate. Urology. 2010; 76:242-246.

8. Karabacak OR, Ipek B, Ozturk $U$, et al. Metabolic evaluation in stone disease metabolic differences between the pediatric and adult patients with stone disease. Urology. 2010; 76:238-241.

9. Alaya A, à coy T, Nouri A, Najjar MF. Nutritional aspects of idiopathic nephrolithiasis in Tunisian children. Arch Ital Urol Androl. 2011; 83:136-140.

10. Kovacevic L, Wolfe-Christensen C, Edwards L, et al. From hypercalciuria to hypocitraturia - a shifting trend in pediatric urolithiasis? J Urol 2012; 188:1623-1627.

11. Tekin A, Tekgul S, Atsu N, et al. A study of the etiology of idiopathic calcium urolithiasis in children: hypocitraturia in the most important risk factor. J Urol. 2000; 164:162-165.

12. Miller LA, Stapleton FB. Urinary volume in children with urolithiasis. J Urol. 1989; 141:918-920.

13. Saez-Torres C, Grases F, Rodrigo D, et al. Risk factors for urinary stones in healthy schoolchildren with and without a family history of nephrolithiasis. Pediatr Nephrol. 2013; 28:639-645.

14. DeFoor W, Asplin J, Jackson E, et al. Urinary metabolic evaluation in normal and stone forming children. J Urol. 2006; 176:17931796.

15. Freycon MT, Frederich A, Durr F, et al. Taux sériques de 25 hydroxyvitamine D chez les nourrissons hospitalés. Rapport avec la calciurie. Pédiatrie. 1989; 44:419-423.

16. Misselwitz J, Hesse V, Markestad T. Nephrocalcinosis, hypercalciuria and elevated serum levels of 1,25-dihydroxyvitamin $D$ in children. Acta Pediatr Scand. 1990; 79:637-643.

17. Veenhuizen L, Donckerwolcke RAMG. Role of 1,25-dihydroxyvit- amin D production in idiopathic hypercalciuria. Child Nephrol Urol. 1991; 11:69-73.

18. Neuhaus TJ, Belzer T, Blau N, et al. Urinary oxalate excretion in urolithiasis and nephrocalcinosis. Arch Dis Child. 2000; 82:322-326.

19. Sarica K, Eryildrim B, Yencilek F, Kuyumcuoglu U. Role of overweight status on stone-forming risk factors in children: a prospective study. Urology. 2009; 73:1003-1007.

20. Eisner BH, Eisenberg ML, Stoller ML. Influence of body mass index on quantitative 24-hour urine chemistry studies in children with nephrolithiasis. J Urol. 2009; 182:1142-1146.

21. Kieran K, Giel DW, Morris BJ, et al. Pediatric urolithiasis - Does body mass index influence stone presentation and treatment? J Urol. 2010; 184:1810-1815.

22. Martinez ME, Villa E, Vazquez Martul M, et al. Influence of calcium intake on calcitriol levels in idiopathic hypercalciuria in children. Nephron. 1993; 65:36-39.

23. Sellers EAC, Sharma A, Rodd C. Adaptation of Inuit children to a low-calcium diet. CMAJ 2003; 168:1141-1143.

24. Polito C, La Manna A, Maiello R, et al. Urinary sodium and potassium excretion in idiopathic hypercalciuria of children. Nephron. 2002; 91:7-12.

25. Osorio AV, Alon US. The relationship between urinary calcium, sodium and potassium excretion and the role of potassium in treating idiopathic hypercalciuria. Pediatrics 1997; 100:675-681.

26. Alon US, Berenbom A. Idiopathic hypercalciuria of childhood: 4to 11-year outcome. Pediatr Nephrol. 2000; 14:1011-1015.

27. Alon US, Zimmerman H, Alon M. Evaluation and treatment of pediatric idiopathic urolithiasis - revisited. Pediatr Nephrol. 2004; 19:516-520.

28. Liern M, Bohorquez M, Vallejo G. Treatment of idiopathic hypercalciuria and its impact on associated diseases. Arch Argent Pediatr. 2013; 111:110-114.

29. Tabel Y, Mir S. The long-term outcomes of idiopathic hypercalciuria in children. J Pediatr Urol. 2006; 2:453-458.

30. Gurgoze MK, Sari MY. Results of medical treatment and metabolic risk factors in children with urolithiasis. Pediatr Nephrol. 2011; 26:933-937.

31. Ross SS, Masko EM, Abern MR, et al. The effect of dietary sodium and fructose intake on urine and serum parameters of stone formation in a pediatric mouse model: a pilot study. J Urol. 2013; 190:1484-1489.

32. Grases F, Saez-Torres C, Rodriguez A, et al. Urinary phytate (Myo-inositol hexaphosphate) in healthy school children and risk of nephrolithiasis. J Ren Nutr. 2014; 24:219-223.

33. Lynch C, Kristjansdottir AG, Te Velde SJ, et al. Fruit and vegetable consumption in a sample of 11-year-old children in ten European countries - the PRO GREENS cross-sectional survey. Public Health Nutr. 2014; 15:1-9.

34. Kim SA, Moore LV, Galuska D, et al. Vital signs: fruit and vegetable intake among children - United States, 2003-2010. Morbid Mortal Wkl Rep. 2014; 63:671-676.

35. Tekin A, Tekgul S, Atsu N, et al. Oral potassium citrate treatment for idiopathic hypocitraturia in children with calcium nephrolithiasis. J Urol. 2002; 168:2572-2574.

36. Nguyen NU, Henriet MT, Dumoulin G, et al. Increase in calciuria and oxaluria after a single chocolate bar load. Horm Metab Res. 1994; 26:383-386.

37. de Mendonça OGC, Martini LA, Baxmann AC, et al. Effects of an oxalate load on urinary oxalate excretion in calcium stone formers. J Ren Nutr. 2003; 13:39-46.

38. Rodgers A. Effect of cola consumption on urinary biochemical and physiochemical risk factors associated with calcium oxalate urolithiasis. Urol Res. 1999; 27:77-81. 
39. Brinkley LJ, Gregory J, Pak CYC. A further study on oxalate bioavalaibility in foods. J Urol. 1990; 144:94-96.

40. Seligson FH, Krummel DA, Apgar JL. Patterns of chocolate consumption. Am J Clin Nutr. 1994; 60S:1060S-1064S.

41. Ogden CL, Kit BK, Carroll MD, Park S. Consumption of sugar drinks in the United States, 2005-2008. NCHS Data Brief. 2011; 7:1-8.

42. Duffey KJ, Huybrechts I, Mouratidou T, et al. Beverage consumption among European adolescents in the HELENA study. Eur J Clin Nutr. 2012; 66:244-252.

43. Borghi L, Meschi T, Amato F, et al. Urinary volume, water and recurrences in idiopathic calcium nephrolithiasis: a 5-year randomized prospective study. J Urol. 1996; 155:839-843.

44. Dent CE, Senior B. Studies on the treatment of cystinuria. Br J Urol. 1955; 27:317-322.

45. Miyagi K, Nakada F, Ohshiro S. Effect of glutamine on cystine excretion in a patient with cystinuria. N Engl J Med. 1979; 301:196-199.

46. Jaeger P, Portmann L, Saunders A, et al. Anticystinuric effects of glutamine and of dietary sodium restriction. N Engl J Med. 1986; 315:1120-1123

47. Norman RW, Manette WA. Dietary restriction of sodium as a means of reducing urinary cystine. J Urol. 1990; 143:1193-1195.

48. Saravakos P, Kokkinou V, Giannatos E. Cystinuria: current diagnosis and management. Urology. 2014; 83:693-699.

\section{Dietary prevention in the elderly}

1. Torpy JM, Lynm C, Glass RM. JAMA patient page. Frailty in older adults. JAMA. 2006; 296:2280.

2. Purser JL, Kuchibhatla MN, Fillenbaum GG, et al. Identifying frailty in hospitalized older adults with significant coronary artery disease. J Am Geriatr Soc. 2006; 54:1674-1681.

3. Usui Y, Matsuzaki S, Matsushita K, et al. Urolithiasisin geriatric patients. J Exp Clin Med. 2003; 28:81.

4. Gentle DL, Stoller ML, Bruce JE, Leslie SW. Geriatric urolithiasis. J Urol. 1997; 158:2221-4.

5. Asper R. Epidemiology and socioeconomic aspects of urolithais. Urol Res. 1984; 12:1.

6. Hiatt RA, Dales LG, Friedman GD, Hunkeler EM. Frequency of urolithiasis in prepaid medical care program. Amer. J. Epidemiol. 115:255-1982.

7. Moesch C, Charmes JP, Gaches F, et al. Crystalluria prevalence in the elderly. Eur J Med. 1993; 2:512.

8. Knoll T, Schubert AB, Fahlenkamp D, et al. Urolithiasis through the ages: data on more than 200,000 urinary stone analyses.J Urol. 2011; 185:1304-11.

9. Krambeck AE1, Lieske JC, Li X, et al. Effect of age on the clinical presentation of incident symptomatic urolithiasis in the general population. J Urol. 2013; 189:158-64.

10. Stoller ML. Gout and stones or stones and gout? J. Urol. 1995; 154:1670.

11. Riese RJ, Sakhaee J. Uric acid nephrolithiasis: Dathogenesis and treatment. J Urol. 1992; 148:7657.

12. Yagisawa T, Hayashi T, Yoshida A, et al. Metabolic characteristics of the elderly with recurrent calcium oxalate stones. BJU Int. 1999; 83:924-8.

13. Freitas Junior CH, Mazzucchi E, Danilovic A, et al. Metabolic assessment of elderly men with urolithiasis. Clinics (Sao Paulo). 2012; 67:457-61.

14. Fardellone P, Sebert JL, Garabedian M, et al. Prevalence and biological consequences of vitamin $D$ deficiency in elderly institutionalized subjects. Rev Rheum. 1995; 62:576.
15. Komar L, Nieves J, Cosman F, et al. Calcium homeostasis of an elderly population upon admission to a nursing home. J Amer Ger Soc. 1993; 41:1057.

16. Taylor EN, Fung TT, Curhan GC. DASH-style diet associates with reduced risk for kidney stones. J Am Soc Nephrol. 2009; 20:2253-9.

17. Ettinger B, Pak CY, Citron JT, et al. Potassium-magnesium citrate is an effective prophylaxis against recurrent calcium oxalate nephrolithiasis. J Urol. 1997; 158:2069-73.

18. Taylor EN, Curhan GC. Body size and 24-hour urine composition. Am J Kidney Dis. 2006; 48:905-15.

19. Messa P, Marangella M, Paganin L, et al. Different dietary calcium intake and relative supersaturation of calcium oxalate in the urine of patients forming renal stones. Clin Sci (Lond). 1997; 93:257-63.

20. Ross AC, Manson JE, Abrams SA, et al. The 2011 report on dietary reference intakes for calcium and vitamin $D$ from the Institute of Medicine: what clinicians need to know. J Clin Endocrinol Metab. 2011; 96:53-8.

21. Taylor EN, Curhan GC. Oxalate intake and the risk for nephrolithiasis. J Am Soc Nephrol 2007; m18: 2198-2204.

22. Sonnenblick M, Friedlander Y, Rosin AJ. Diuretic-induced severe hyponatremia. Review and analysis of 129 reported patients. Chest. 1993; 103:601-6.

\section{Correspondence}

Domenico Prezioso, MD - dprezioso@libero.it (Corresponding Author)

Pasquale Strazzullo,MD - strazzul@unina.it

Tullio Lotti, MD - tulliolotti@hotmail.it

Giampaolo Bianchi, MD - bianchi.giampaolo@unimore.it

Loris Borghi, MD - loris.borghi@unipr.it

Paolo Caione, MD - paolo.caione@opbg.net

Marco Carini, MD - carini@unif.it

Renata Caudarella, MD - renata.caudarella@alice.it

Giovanni Gambaro, MD - giovanni.gambaro@rm.unicatt.it

Marco Gelosa, MD - marco.gelosa@yahoo.it

Andrea Guttilla, MD - andrea.guttilla@gmail.com

EsterIlliano, MD - ester.iliano@inwind.it

Martino Marangella, MD - mmarangella@alice.it

Tiziana Meschi, MD - tiziana.meschi@unipr.it

Piergiorgio Messa, MD - pmessa@policlinico.mi.it

Roberto Miano,MD - mianor@virgilio.it

Giorgio Napodano, MD

Antonio Nouvenne, MD - antonio.nouvenne@alice.it

Domenico Rendina, MD - domenico.rendina@libero.it

Francesco Rocco, MD - francesco.rocco@unimi.it

Marco Rosa, MD - marcorosa1983@gmail.com

Roberto Sanseverino,MD - roberto.sanseverino@alice.it

Annamaria Salerno, MD - annamaria.salerno@unicampus.it

Sebastiano Spatafora, MD - s.spatafora@me.com

Andrea Tasca, MD - andrea.tasca@ulssvicenza.it

Andrea Ticinesi, MD - andrea.ticinesi@studenti.unipr.it

Fabrizio Travaglini, MD - effetrava@hotmail.com

Alberto Trinchieri, MD - a.trinchieri@ospedale.lecco.it

Giuseppe Vespasiani, MD - vespasiani@uniroma2.it

Filiberto Zattoni, MD - filiberto.zattoni@unipd.it 